\title{
Cart3D Analysis of Plume and Shock Interaction Effects on Sonic Boom
}

\author{
Raymond Castner ${ }^{1}$, \\ NASA Glenn Research Center, Cleveland, Ohio, 44135
}

\begin{abstract}
A plume and shock interaction study was developed to collect data and perform CFD on a configuration where a nozzle plume passed through the shock generated from the wing or tail of a supersonic vehicle. The wing or tail was simulated with a wedge-shaped shock generator. Three configurations were analyzed consisting of two strut mounted wedges and one propulsion pod with an aft deck from a low boom vehicle concept. Research efforts at NASA were intended to enable future supersonic flight over land in the United States. Two of these efforts provided data for regulatory change and enabled design of low boom aircraft. Research has determined that sonic boom is a function of aircraft lift and volume distribution. Through careful tailoring of these variables, the sonic boom of concept vehicles has been reduced. One aspect of vehicle tailoring involved how the aircraft engine exhaust interacted with aft surfaces on a supersonic aircraft, such as the tail and wing trailing edges. In this work, results from Euler CFD simulations are compared to experimental data collected on sub-scale components in a wind tunnel. Three configurations are studied to simulate the nozzle plume interaction with representative wing and tail surfaces. Results demonstrate how the plume and tail shock structure moves with increasing nozzle pressure ratio. The CFD captures the main features of the plume and shock interaction. Differences are observed in the plume and deck shock structure that warrant further research and investigation.
\end{abstract}

\section{Nomenclature}

$\mathrm{D} \quad=$ test nozzle outer diameter, inches

$\mathrm{NPR}=$ nozzle pressure ratio $=\mathrm{P}_{\mathrm{t}} / \mathrm{P}_{\infty}$

$\mathrm{P} \quad=$ local static pressure, psia

$\mathrm{P}_{\mathrm{t}} \quad=$ total pressure in nozzle, psia

$\mathrm{P}_{\infty} \quad=$ free stream static pressure, psia

$\Delta \mathrm{P}=\left(\mathrm{P}-\mathrm{P}_{\infty}\right) / \mathrm{P}_{\infty}$

$\mathrm{x} \quad=$ axial distance from jet simulator nozzle exit plane, inches

$\mathrm{y} \quad=$ distance from nozzle centerline, inches

\section{Introduction}

Two major barriers exist to enable supersonic commercial flight over land in the continental United States. First is a regulatory change from the FAA, allowing supersonic flight over land within a specified noise or disturbance level. Second is the ability to design aircraft that meet a low sonic boom noise or disturbance level. NASA has conducted research to reduce the sonic boom which is largely governed by the lift and volume of the supersonic aircraft. Boom can be reduced through careful tailoring and optimization of the configuration, made possible by modern CFD and computational tools. The design and wind tunnel validation of conceptual aircraft has been performed under recent NASA and industry partnerships ${ }^{1,2}$.

One aspect of the optimization involves how the aircraft engine integrates with the airframe, and specifically how the exhaust nozzle plume interacts with the shock waves from the vehicle tail and wing trailing edge. In some conceptual aircraft configurations, the engines are mounted on top of the wing. In this way the wing acts as a deck to shield the disturbance caused by the engine from propagating below the aircraft. Building on past work, both CFD analysis and an experiment were performed to study how a nozzle plume interacted with a simulated tail shock.

\footnotetext{
${ }^{1}$ Aerospace Engineer, Inlets and Nozzles Branch, 21000 Brookpark Road, AIAA Associate Fellow.
} 
Early work on an isolated exhaust nozzle contribution to sonic boom included a report by Putnam and Capone $^{3}$, and another by Barger and Melson ${ }^{4}$. In the work by Putnam and Capone, nozzles were tested from a fully-expanded Mach 1.7 nozzle to a fully-expanded Mach 2.9 nozzle. Their study was conducted in a wind tunnel, where an axial survey of near-field pressure measurements were made at one nozzle diameter above the model. Wind tunnel conditions were Mach 2.2 at a simulated altitude of 50,000 feet.

In 2009, Computational Fluid Dynamics (CFD) analysis was performed ${ }^{5}$ where over-expanded and underexpanded operation of a nozzle had an effect on the $\mathrm{N}$-wave boom signature. The work demonstrated the feasibility of reducing the magnitude of the sonic boom $\mathrm{N}$-wave by controlling the nozzle plume interaction with the nozzle boat-tail flow structure. Under-expanded exhaust nozzle flow had a favorable result on near field pressure signatures, suggesting that the nozzle plume shock location could be controlled through control of nozzle pressure or nozzle divergent section geometry.

The study of exhaust nozzle plume effect on sonic boom has progressed from analysis and testing of an isolated nozzle to analysis of slot nozzles ${ }^{6}$ and engine-wing-body models ${ }^{7,8}$. These studies also demonstrated how the nozzle lip shock from an under-expanded nozzle plume could suppress the nozzle boat-tail expansion and reduce the strength of the trailing shock.

Two recent CFD and experimental studies ${ }^{9,10}$ have studied the interaction of an exhaust nozzle plume and a shock wave generated by simple wedge-shaped shock generators. In both studies, the wedge pressure signature was modified by the presence of the plume and the plume path was modified by the pressure disturbance from the wedge. This implies that detailed computations of the nozzle plume should be modeled during design of modern low boom supersonic transport configurations.

The capability to test small-scale models in NASA GRC's 1-foot by 1-foot supersonic wind tunnel (1x1 SWT) was developed to validate results obtained for supersonic nozzle concepts. This capability was utilized for a fundamental study of the nozzle plume and shock interaction effects ${ }^{11}$. Analysis was performed on the experimental configuration using the Cart3D CFD code. The purpose of this report is to present the comparisons between CFD and wind tunnel test results. The present work studied the effects of a nozzle exhaust plume with a simulated tail shock. The tail shock was generated by two methods: (1) a simple wedge-shaped shock generator and (2) an aft deck from a simulated engine nacelle and vehicle. Comparisons are made to near field pressure signatures measured in the wind tunnel, which directly correlate to the sonic boom contribution of the nozzle and tail shock interaction.

\section{Test Setup}

The experiment included three configurations of the Putnam 'Nozzle 6' and a shock generator: (1) a 5degree shock generator with a 6-in. chord, (2) a 5-degree shock generator with a 1.5 in. chord, and (3) an aft deck with a length of $x / D=0.5$. This section is to review the wind tunnel model, instrumentation, and shock generator geometry. Wind tunnel testing was conducted at Mach 1.96, and nozzle operating conditions are provided in Table 1.

\section{II.a. Model}

The wind tunnel model used to hold the exhaust nozzle consisted of three major parts: the upper plenum, the strut, and the lower plenum (as displayed in Fig. 1). A photo of the rig installation is also provided. The upper plenum design was 1-inch outer diameter, and had an overall length from the nosecone to the nozzle exit of 8.21 inches. The support strut was 0.35 inch in thickness and contained nine passages to supply airflow. Air supply lines were 0.25 inch diameter, and the passages supplied 90 psia of pressure to achieve 20 psia at the nozzle inlet for test conditions at 50,000 ft altitude. To accommodate larger nozzles and testing at lower altitudes, the maximum design pressure at the strut was 233 psia, to achieve 52 psia at the nozzle inlet. Choked orifice holes were needed on top of the strut supply lines to obtain required mass flow. Orifice holes were 0.210 inch diameter. 450 psig pressurized air was supplied to the bottom of the strut. 


\section{II.b. Instrumentation}

Nozzle pressure ratio (NPR) was determined based on mass flow measurement and nozzle throat diameter. Sonic flow equations for a venturi were used from Blevins ${ }^{12}$ to perform this calculation. An external static pressure probe was designed to survey near-field static pressure profiles at one nozzle diameter above the rig centerline. The static pressure probe was mounted on an airfoil probe support and a sliding ball screw actuator from the opposite side of the tunnel. The probe passed through the tunnel sidewall and the actuator was installed in an enclosure to match the tunnel pressure. The overall assembly, showing the probe location, is provided in Fig. 2.

The static pressure probe had a capability to travel axially 7.4 inches to capture pressure profiles, starting 0.7 inches downstream of the nozzle exit and extending downstream to where the plume interacts with the tunnel/wall shock reflection. Two static pressure probes were built, a 10-degree cone probe and a design based on Pinckney ${ }^{13}$. The 10-degree cone probe design, in Fig. 3, had difficulty capturing shock waves. This difficulty was demonstrated by a rounding of the peaks where shock waves occur, caused by the high cone angle and the long distance between the probe tip and the static pressure measurement ports where the measurement was not in the same flow environment as the probe tip. The Pinckney probe design had less sensitivity to angle of attack while achieving similar relaxation of static pressure at the location of the measurement ports. However, static pressure data collected with the Pinckney probe demonstrated a constant offset in $\Delta \mathrm{P} / \mathrm{P}$ of -0.8 when tested in an empty tunnel, suggesting that the Pinckney probe has an offset in the $\Delta \mathrm{P} / \mathrm{P}$ measurement. These probes were mounted on a $3 / 8$ inch thick airfoil strut, allowing 5.625 inches of probe length between the static pressure holes and the airfoil support. For all experimental results presented, the Pinckney probe was used. The model was placed between two transparent sidewalls in the 1 -foot by 1 -foot SWT for schlieren photography.

\section{II.c. Nozzle}

The test nozzle was based on 'Nozzle 6' from Putnam and Capone. The nozzle was scaled to a 1 inch outer diameter, and was designed to be threaded onto the small jet rig (Fig. 3) for the 1x1 SWT. The design NPR was 8.12 with a fully expanded jet Mach number of 2.024; the boat-tail angle was 5-degrees. The nozzle is shown in Fig. 4.

\section{II.d. Wedge geometry}

Three shock generator wedges were fabricated from 17-4 stainless steel to provide both a leading edge and trailing edge shock that would intersect with the nozzle plume. One wedge was built with a 5-degree wedge angle (10-degree inclusive), a second wedge was built with a 2.5-degree wedge angle (5-degree inclusive, see Fig. 5).

These two wedges were 6 inches in overall chord, 8 inches in span, and were mounted on a diamond shaped support strut 4 inches high from the wind tunnel wall. The third wedge was 1.5 inch in overall chord, 3.5 inches in span, and was also mounted on a diamond shaped support strut 4 inches from the wall. The wedges possessed sharp leading and trailing edges with a maximum radius of 0.005 in.

\section{II.e. Nacelle and Aft Deck Geometry}

Three nacelle shapes were fabricated using acrylonitrile butadiene styrene (ABS) material and three dimensional printing technology; the shapes were designed to fit over the existing 1 in. diameter upper plenum and nozzle. These nacelle shapes were designed to simulate the outer mold line of a notional propulsion pod. In many of the vehicle design concepts for a low sonic boom aircraft, the propulsion pod would be mounted on the top of the fuselage, utilizing an aft deck for sonic boom and noise shielding. For the present study, the deck extended past the nozzle for a distance of 0.5 nozzle diameter (x/D=0.5) (Fig. 6).

\section{III.a. Geometry}

\section{CFD Analysis}

CFD analyses were conducted on three experimental geometries: (1) a 5-degree shock generator with a 6in. chord, (2) a 5-degree shock generator with a 1.5 in. chord, and (3) an aft deck with a length of $x / D=0.5$. 


\section{III.b. CFD Code}

Cart $3 \mathrm{D}^{14,15}$ is a high-fidelity analysis package for conceptual and preliminary aerodynamic design that provides solution to the Euler equations. It allows users to perform automated CFD analysis on complex geometry. Geometry for Cart3D is represented by surface triangulations. These may be generated from within a ComputerAided Design (CAD) system, from legacy surface triangulations or from diagonalized (diagonal added to each quadrilateral face) structured surface grids. Cart3D uses an embedded multilevel Cartesian mesh to discretize the space surrounding the geometry and determines the surface geometry out of the set of "cut-cells" which intersect the surface triangulation. The flow solver is parallelized via Open Multi-Processing (OPENMP) and can take advantage of multi-core hardware. Solutions were obtained using the adjoint-based mesh adaptation module ${ }^{16-18}$. This module uses adjoint-weighted residual error-estimates to drive mesh adaptation. Once a user specifies the output function of interest, such as lift, drag, or off-body pressures along a line with a corresponding error tolerance, the module automatically refines the mesh to drive the remaining numerical errors below the requested tolerance. This module combined with domain rotation to nearly align the mesh with the Mach angle has been validated for sonic boom prediction by Wintzer ${ }^{19}$ and others with and without adaptation ${ }^{20-23}$. The adaptation module allows greatly reduced mesh generation and analysis time and offers effective use of computational resources for an accurate solution.

\section{III.c. Domain and Flow Conditions}

Surface geometry was generated for the wind tunnel model and the nozzle flow field was simulated with a pressure boundary condition as outlined in Table 1. Simulations were run at Mach 1.96. The computational domain was contained within the 12.1 inch by 12 inch wind tunnel walls, starting at $x=-16$ inches to $x=17$ inches, where $\mathrm{x}=0$ was the nozzle exit plane. Four Cart3D 'line sensors' were used to drive mesh adaptation: (1) downstream of the nozzle exit, (2) one diameter above the nozzle centerline, (3) one inch above from the tunnel 'floor', and (4) one inch below the tunnel 'ceiling.' Seven levels of grid adaptation were completed and the final mesh contained approximately 8.1 million grid points.

\section{Results}

CFD results are provided for the three configurations of the Putnam 'Nozzle 6' and a shock generator: (1) a 5-degree shock generator with a 6-in. chord, (2) a 5-degree shock generator with a 1.5 in. chord, and (3) an aft deck with a length of $\mathrm{x} / \mathrm{D}=0.5$.

\section{IV.a. 5-Degree Shock Generator with 6-in. Chord}

Simulations using the Cart3D CFD code were performed with nozzle operating conditions from NPR=8 to $\mathrm{NPR}=14$ using the 6 inch long wedge-shaped shock generator (wedge). Mach number contours for the entire solution are plotted in Fig. 7, along with an image of the final adapted Cart3D computational mesh. A close-up of the Mach number contours is provided in Fig. 8, along with the pressure signature $(\Delta \mathrm{P} / \mathrm{P})$ extracted one nozzle diameter away from the nozzle centerline. The nozzle lip shock can be observed at $\mathrm{x} / \mathrm{D}=1$. Two observations can be made at the lip shock location: (1) the lip shock gets stronger with increasing NPR, and (2) the lip shock moves upstream with increasing NPR. These observations are consistent with previous studies. The leading edge shock from the wedge was located at $\mathrm{x} / \mathrm{D}=5$. The influence of the nozzle plume was observed on the leading edge shock where: (1) the leading edge shock moved downstream with increasing NPR, and (2) the leading edge shock was stronger with increasing NPR $(\Delta \mathrm{P} / \mathrm{P}$ increased from 0.3 to 0.4$)$. At $\mathrm{x} / \mathrm{D}=8$ the pressure signature exhibits interference caused by a reflection of an upstream disturbance off the wind tunnel wall. Due to this reflection, the wedge expansion and trailing edge shock could not be studied for this configuration.

In Fig. 9, the experimental pressure profiles are plotted for comparison to the Cart3D profiles. In these profiles, the lip shock was not captured due to the limited travel of the probe actuator system. The leading edge shock from the wedge was captured at $\mathrm{x} / \mathrm{D}=5$, as was the interference from the wind tunnel reflections at $\mathrm{x} / \mathrm{D}=6$. Wind tunnel reflections were stronger in the experiment and were located at a different location due to the interaction with the wind tunnel boundary layer. Individual comparisons between the experimental data and the CFD, for each NPR, are provided in Fig. 10. At all NPRs, inviscid CFD results show the secondary shock off the nozzle plume was observed at a location behind the experimental data. This effect was due to the lack of viscous 
effects, as no boundary layer buildup was present at the nozzle exit. The location of the wedge leading edge shock was captured for each NPR, with the CFD trailing the experiment, again due to lack of viscous effects in the inviscid simulations.

\section{IV.b. 5 Degree Shock Generator with 1.5 in. Chord}

Simulations were performed from NPR=6 to NPR=14 using the 1.5 inch long wedge-shaped shock generator (wedge). Mach number contours for the entire CFD solution are plotted in Fig. 11 and the final CFD mesh is also provided. A close-up of the Mach number contours are provided in Fig. 12, where the $\Delta \mathrm{P} / \mathrm{P}$ pressure profile is also provided for direct comparison. As in the previous case, the nozzle lip shock is observed at $\mathrm{x} / \mathrm{D}=1$. The same trends are present and will not be repeated here. The leading edge shock from the wedge was located at $\mathrm{x} / \mathrm{D}=4$. The influence of the nozzle plume was again observed on the leading edge shock where: (1) the leading edge shock moves downstream with increasing NPR, and (2) the leading edge shock gets stronger with increasing $\operatorname{NPR}(\Delta \mathrm{P} / \mathrm{P}$ increases from 0.15 to 0.25$)$. The trailing edge shock from the wedge was located at $\mathrm{x} / \mathrm{D}=7$. In this study, the shorter wedge length (combined with a new location) allowed both the leading and trailing edge shocks to be measured. The trailing edge shock was also influenced by the nozzle pressure ratio, where the shock moved aft as NPR was increased. The reflection from the wind tunnel wall at $\mathrm{x} / \mathrm{D}=8$ was downstream of the trailing edge shock.

In Fig. 13, the experimental pressure profiles $(\Delta \mathrm{P} / \mathrm{P})$ were plotted for comparison to the Cart3D pressure profiles. In these profiles, the lip shock was again not captured due to the limited travel of the probe actuator system. The leading edge shock from the wedge was captured at $\mathrm{x} / \mathrm{D}=4$. In the experiment the shock reflection and the trailing edge shock at $\mathrm{x} / \mathrm{D}=7$ appeared to merge. Individual comparisons for each NPR are provided in Fig. 14 . At all NPRs, the location of the leading edge shock was captured, with the CFD trailing the experiment. The trailing edge shock was also captured in both $\mathrm{CFD}$ and experiment at $\mathrm{X} / \mathrm{D}=7$. In the experimental data for all NPRs, the trailing shock merged with the shock reflection from the tunnel wall; while in CFD the shock reflection was located at $x / D=8$. The difference in the location of the shock reflection was due to the interaction with the boundary layer buildup on the $1 \mathrm{x} 1 \mathrm{SWT}$ wall, which was not simulated with the inviscid CFD solution.

IV.c. Aft Deck with Length of $\mathrm{x} / \mathrm{D}=0.5$

Simulations were performed on the aft deck shock generator $\mathrm{x} / \mathrm{D}=0.5$ configuration (deck), from $\mathrm{NPR}=6$ to $\mathrm{NPR}=14$. Mach number contours for the entire solution are plotted in Fig. 15 and the adapted final CFD mesh is also provided. A close-up of the Mach number contours, along with the pressure profile $(\Delta \mathrm{P} / \mathrm{P})$ at 1 nozzle diameter from the nozzle centerline are provided in Fig. 16. For the deck configuration, the typical signature from the nozzle lip shock was shielded from the sensor. In its place is a shock from the deck, located at $\mathrm{x} / \mathrm{D}=0.75$. At this location, the NPR influenced both the strength and location of the deck shock wave, where (1) the deck shock moves upstream with increasing NPR and (2) the deck shock gets stronger with increasing NPR ( $\triangle \mathrm{P} / \mathrm{P}$ increases from 0.05 to 0.21 ). The secondary plume shock (or barrel shock) was also affected by increasing NPR in both magnitude and location $(\Delta \mathrm{P} / \mathrm{P}$ changed from 0.19 to -0.10$)$.

In Fig. 17, the experimental pressure profiles are plotted for comparison to the CFD profiles. In these profiles, the deck shock was located at $\mathrm{x} / \mathrm{D}=0.75$. The experimental data followed the same trends as the $\mathrm{CFD}$, but with reduced shock strength; trends include movement of the deck shock upstream with increasing NPR and increasing shock strength with increasing NPR. Movement of the secondary plume shock was also observed in the experiment and was consistent with the CFD. However, large differences in shock strength can be observed in the individual comparisons (Fig. 19). For each NPR, the experimental shock strength was lower than in the CFD.

\section{Conclusions}

A plume and shock interaction study was developed to collect data and perform CFD on a configuration where a nozzle plume passed through the shock generated from the wing or tail of a supersonic vehicle. The wing or tail was simulated with a wedge-shaped shock generator. Three configurations are presented consisting of two strutmounted wedges and one propulsion pod with an aft deck from a low boom vehicle concept. A CFD study was performed with the Cart3D code to study the effects of an exhaust nozzle plume and shock wave interaction. CFD 
results were compared to test data collected in the 1-foot by 1-foot SWT. Results demonstrate how the CFD captured the interaction of the jet plume and the shock generated by the wedge.

Experimental results show: (1) for the 5-degree wedge experiment with 6 inch chord, the leading edge shock moved downstream with increasing NPR, and increased in magnitude, (2) for the aft deck configuration, the upper and lower deck shock rotated about the deck; the lower deck shock moved upstream with increasing NPR and the upper deck shock moved downstream with increasing NPR, and (3) the location and thickness of the shock was modified by the presence of the nozzle plume, when compared to the wedge alone.

CFD results show: (1) for the 5-degree wedge experiment with 1.5 inch chord, the leading edge shock moved downstream with increasing NPR, and increased in magnitude, (2) for the aft deck configuration, the lower deck shock rotated about the deck and moved upstream with increasing NPR, and (3) when compared to the experiment, the shock location from the wedge was located downstream due to effects from the boundary layer on the nozzle and wedge, which moved the experimental shockwaves upstream.

Cart3D and experimental comparisons with the deck suggest that the flow turning around the deck is different in the experiment than in the CFD. In Figs. 15 and 16 the jet plume appeared to have a significant vector angle or offset when compared to the nozzle centerline. However, the jet plume was not visible in the experimental schlieren images (due to the low density gradients in the plume) and it was not possible to observe if the vectoring was present in the experiment. Further experimental data is warranted to study these differences, such as plume exit profile measurements. Better understanding of the differences between the CFD and experiment would be valuable to understand how the jet plume interaction might affect vehicle trim and aerodynamics due to the plume vector angle, thrust vectoring, and the effect of the plume on vehicle upper deck surface. Comparisons to a viscous CFD analysis are recommended to understand the interaction of the jet plume with the aft deck in the presence of boundary layer effects.

Cart3d is often used for optimization to design a vehicle with a low sonic boom signature. Cart3d is attractive due to its ability to perform analysis on many vehicle designs with manageable time and computation resources. In the case of these wedge shock and plume interactions, Cart3D captured the movement of the shock with increasing NPR. Simulations also predicted the location of the wedge shock in this configuration at a location slightly downstream of the experiment, due to the inviscid analysis where the boundary layers modify the locations of the shock waves off the wedge. Studies may be warranted at a larger scale, where the boundary layers may be smaller compared to the geometry. In the case with the aft deck, Cart3d also captured the movement of the shock with increasing NPR. However, significant differences in the shock strength suggest a viscous analysis may play a more important role in future high speed vehicle design.

\section{Acknowledgments}

This work was funded by the NASA Advanced Air Vehicles Program, Commercial Supersonic Technology Project.

\section{References}

${ }^{1}$ Morgenstern, J., Buonanno, M., Norstrund, N., "N+2 Low Boom Wind Tunnel Model Design and Validation," AIAA-2012-3217, June 2013.

${ }^{2}$ Magee, T., Fugal, S., Fink, L., Shaw, S., "Boeing N+2 Supersonic Experimental Validation Phase II Program," AIAA-2014-2137, June 2014.

${ }^{3}$ Putnam, L. and Capone, F., "Experimental Determination of Equivalent Solid Bodies to Represent Jets Exhausting into a Mach 2.20 External Stream," NASA TN-D-5553.

${ }^{4}$ Barger, R. L. and Melson, N. D., "Comparison of Jet Plume Shape Predictions and Plume Influence on Sonic Boom Signature," NASA TP-3172.

${ }^{5}$ Castner, R. S., "Exhaust Nozzle Plume Effects on Sonic Boom,” Journal of Aircraft, 2012, vol. 49: 415-422, March-April 2012.

${ }^{6}$ Castner, R. S., "Slot Nozzle Effects for Reduced Sonic Boom on a Generic Supersonic Wing Section," AIAA2010-1386, Jan. 2010.

${ }^{7}$ Castner, R. S., "Analysis of Exhaust Plume Effects on Sonic Boom for a 59-Degree Wing Body Model," AIAA2011-917, Jan. 2011. 
${ }^{8}$ Castner, R. S., "Exhaust Plume Effects on Sonic Boom for a Delta Wing and Swept Wing-Body Model," AIAA2012-1033, Jan. 2012.

${ }^{9}$ Castner, R. S., Elmiligui, A., and Cliff, S. "Exhaust Nozzle Plume and Shock Wave Interaction," AIAA-2013-12, Jan 2013.

${ }^{10}$ Castner, R.S., Zaman, K. Q., Fagan, A., and Heath, C., "Wedge Shock and Nozzle Exhaust Plume Interaction in a Supersonic Jet Flow," AIAA-2014-0232, Jan 2014.

${ }^{11}$ Castner, R. S., Elmiligui, A., Cliff, S., and Winski, C., "Plume and Shock Interaction Effects on Sonic Boom in the 1-foot by 1-foot Supersonic Wind Tunnel," AIAA-2015-1046, Jan 2015

${ }^{12}$ Blevins, R. D., “Applied Fluid Dynamics Handbook,” Krieger, Florida, 1992 pp 126-135.

${ }^{13}$ Pinckney, S. Z., "A Short Static Pressure Probe Design for Supersonic Flow,” NASA TN D-7978.

${ }^{14}$ Aftosmis, M. J., Berger, M. J., and Melton, J. E., "Robust and Efficient Cartesian Mesh Generation for Component-Based Geometry," AIAA Journal, Vol. 36, No. 6, 1998, pp. 952-960.

${ }^{15}$ Aftosmis, M. J., Berger, M. J., and Adomavicius, G., "A Parallel Multilevel Method for Adaptively Refined Cartesian Grids with Embedded Boundaries," AIAA Paper 2000-0808, Jan. 2000.

${ }^{16}$ Aftosmis, M. J.; and Berger, M. J., "Multilevel Error Estimation and Adaptive H-Refinement for Cartesian Meshes with Embedded Boundaries," AIAA Paper 2002-0863, NV, Jan. 2002.

${ }^{17}$ Nemec, M., and Aftosmis, M. J., "Adjoint Error-Estimation and Adaptive Refinement for Embedded-Boundary Cartesian Meshes,” AIAA Paper 2007-4187, Jun. 2007.

${ }^{18}$ Nemec, M., Aftosmis, M. J., and Wintzer, M., "Adjoint-Based Adaptive Mesh Refinement for Complex Geometries,” AIAA Paper 2008-0725, Jan. 2008.

${ }^{19}$ Wintzer, M., Nemec, M., and Aftosmis, M., "Adjoint-Based Adaptive Mesh Refinement for Sonic Boom Prediction," AIAA-2008-6593, Aug. 2008.

${ }^{20}$ Cliff, S. E., Thomas, S. D., McMullen, M. S., Melton, J.E., and Durston, D. A., “Assessment of Unstructured Euler Methods for Sonic Boom Pressure Signatures Using Grid Refinement and Domain Rotation Methods,” NASA/TM-2008-214568, Sept. 2008.

${ }^{21}$ Aftosmis, Michael, Nemec, Marian, and Cliff, Susan, "Adjoint-Based Low-Boom Design with CART3D (Invited), AIAA-2011-3500, Jun.2011.

${ }^{22}$ Elmiligui, Alaa, Cliff, Susan, Aftosmis, Michael, Nemec, Marian, Parlette, Edward, Wilcox, Floyd, and Bangert, Linda, "Sonic Boom Computations for a Mach 1.6 Cruise Low Boom Configuration and Comparisons with Wind Tunnel Data (Invited), AIAA-2011-3496, Jun. 2011.

${ }^{23}$ Elmiligui, A., Cliff, S., Wilcox, F., and Thomas, S. "Numerical Predictions of Sonic Boom Signatures for Straight Line Segmented Leading Edge Model", Seventh International Conference on Computational Fluid Dynamics, ICCFD7-2004, Big Island, HI, Jul. 9-13, 2012. 
Table 1, Flow Conditions

\begin{tabular}{cccc}
\multicolumn{4}{c}{ Wind Tunnel Conditions } \\
$\begin{array}{c}\mathbf{P}_{\mathbf{s}} \\
\text { psia })\end{array}$ & $\begin{array}{c}\mathbf{P}_{\mathbf{t}} \\
(\text { psia })\end{array}$ & Mach number & $\begin{array}{c}\mathbf{T}_{\mathbf{t}} \\
\left({ }^{\circ} \text { Rankine }\right)\end{array}$ \\
\hline 1.68 & 12.4 & 1.96 & 530
\end{tabular}

Nozzle Conditions

\begin{tabular}{cccc} 
NPR & $\begin{array}{c}\mathbf{P}_{\mathbf{t}} \\
(\mathbf{p s i a})\end{array}$ & $\begin{array}{c}\text { Mass Flow } \\
(\mathbf{l b m} / \mathbf{s e c})\end{array}$ & $\begin{array}{c}\mathbf{T}_{\mathbf{t}} \\
\left({ }^{\circ} \text { Rankine }\right)\end{array}$ \\
\hline 6 & 10.08 & 0.081 & 530 \\
8 & 13.44 & 0.109 & 530 \\
10 & 16.80 & 0.135 & 530 \\
12 & 20.16 & 0.163 & 530 \\
14 & 23.52 & 0.187 & 530
\end{tabular}




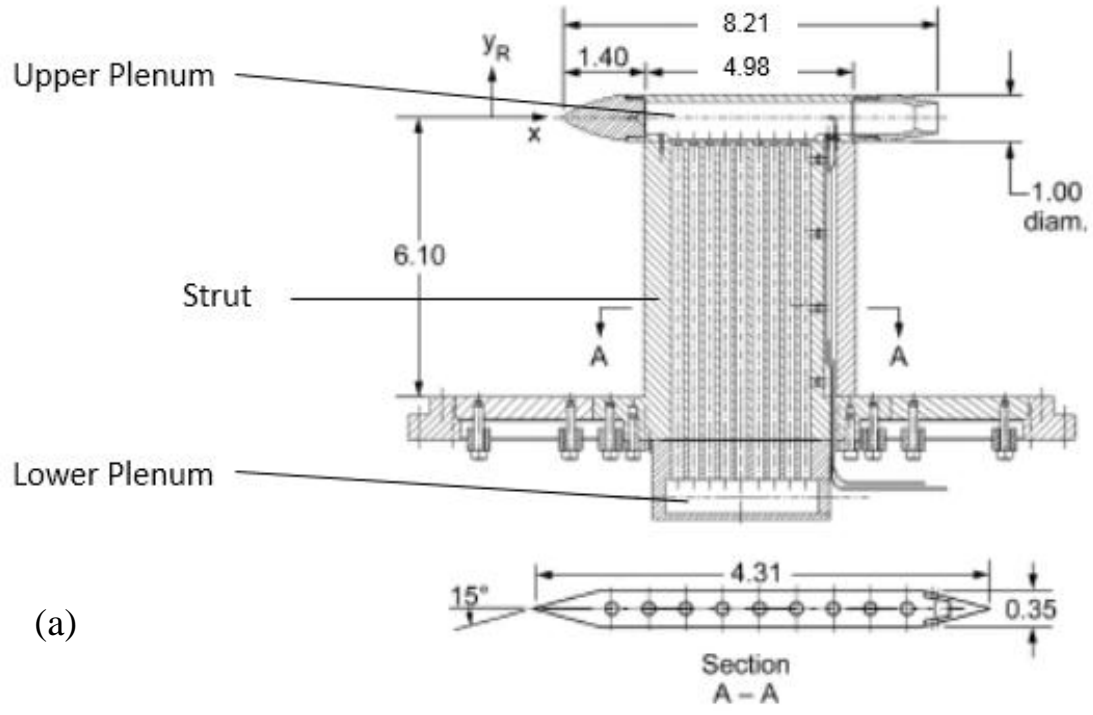

(b)

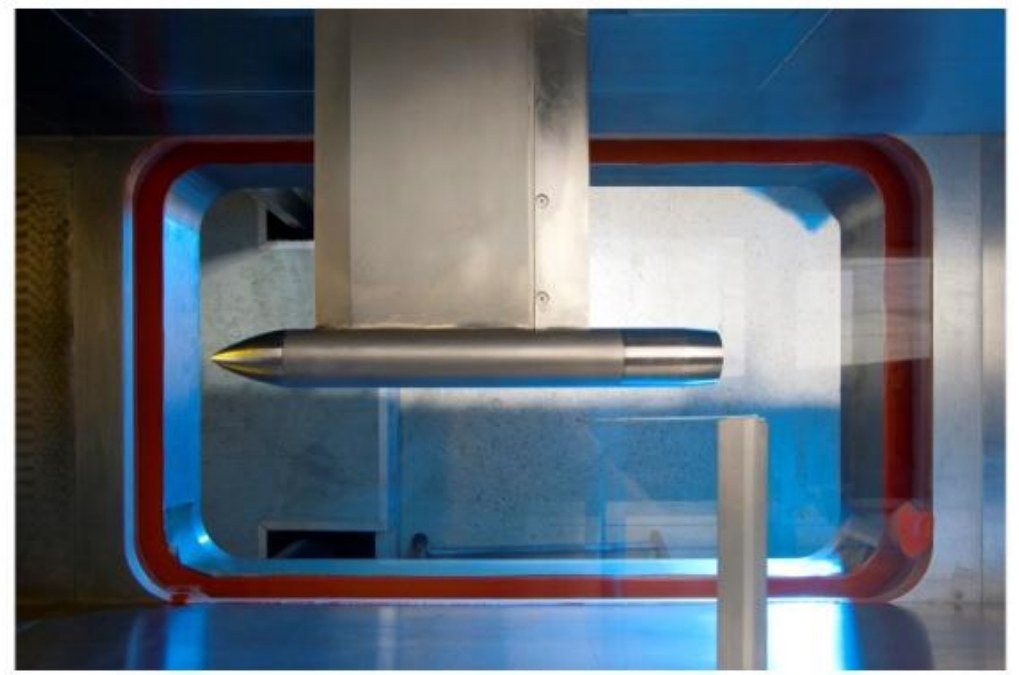

Figure 1. Wind tunnel model (a) layout, dimensions in inches (NASA Glenn Drawing G30008MRA100) and (b) photograph. 


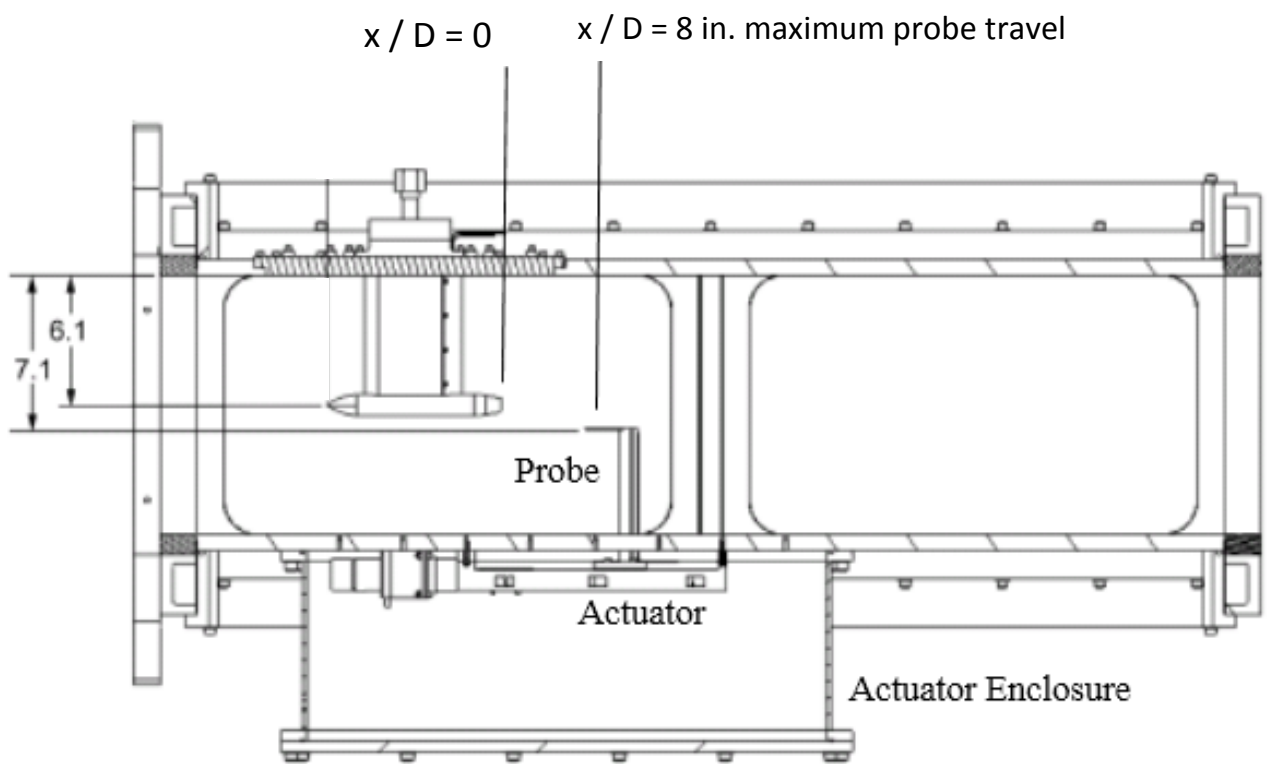

Figure 2. Wind tunnel and model cross section as installed in the 1-foot by 1-foot SWT test section. Dimensions in inches.

(NASA Glenn drawing G30008MRA000).

(a)

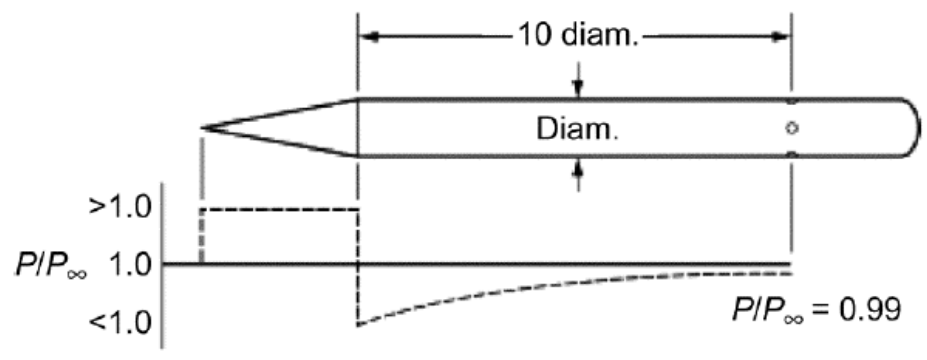

(b)

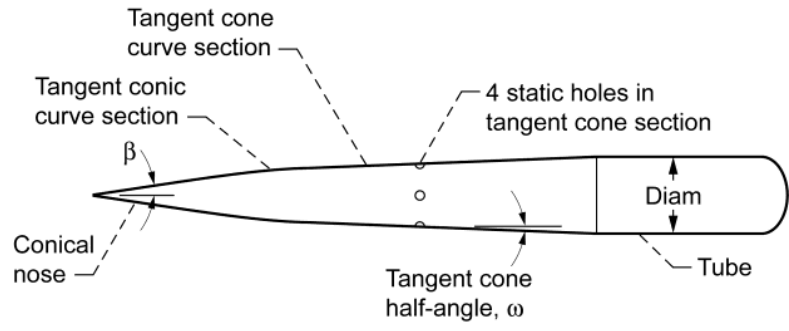

Figure 3. (a) 10-degree cone probe and (b) Pinckney probe design ( $\beta=10 ; \omega=1.5$ ). 

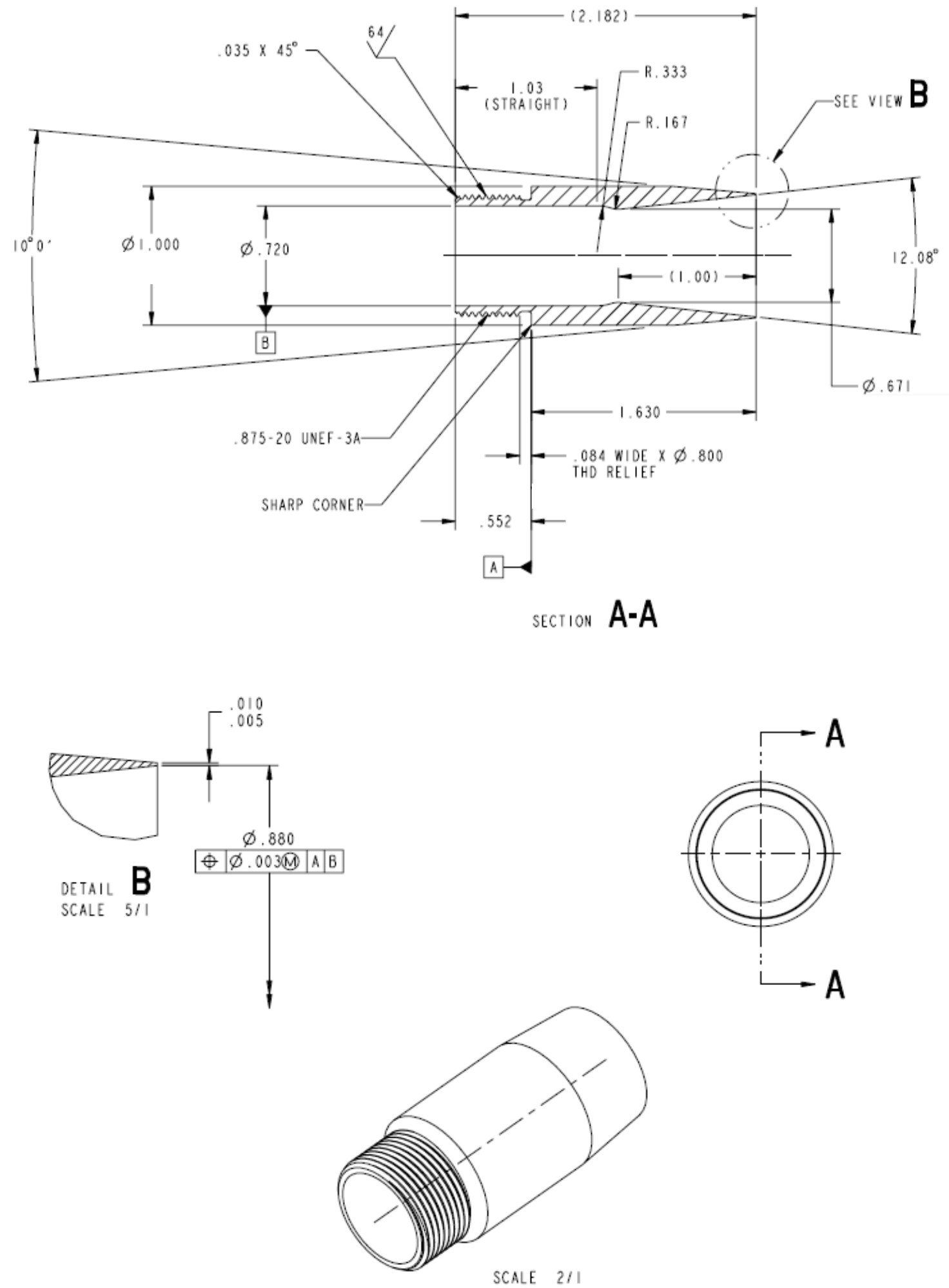

Figure 4. 'Nozzle 6' test nozzle.

(NASA Glenn Drawing G30008MRA125). 

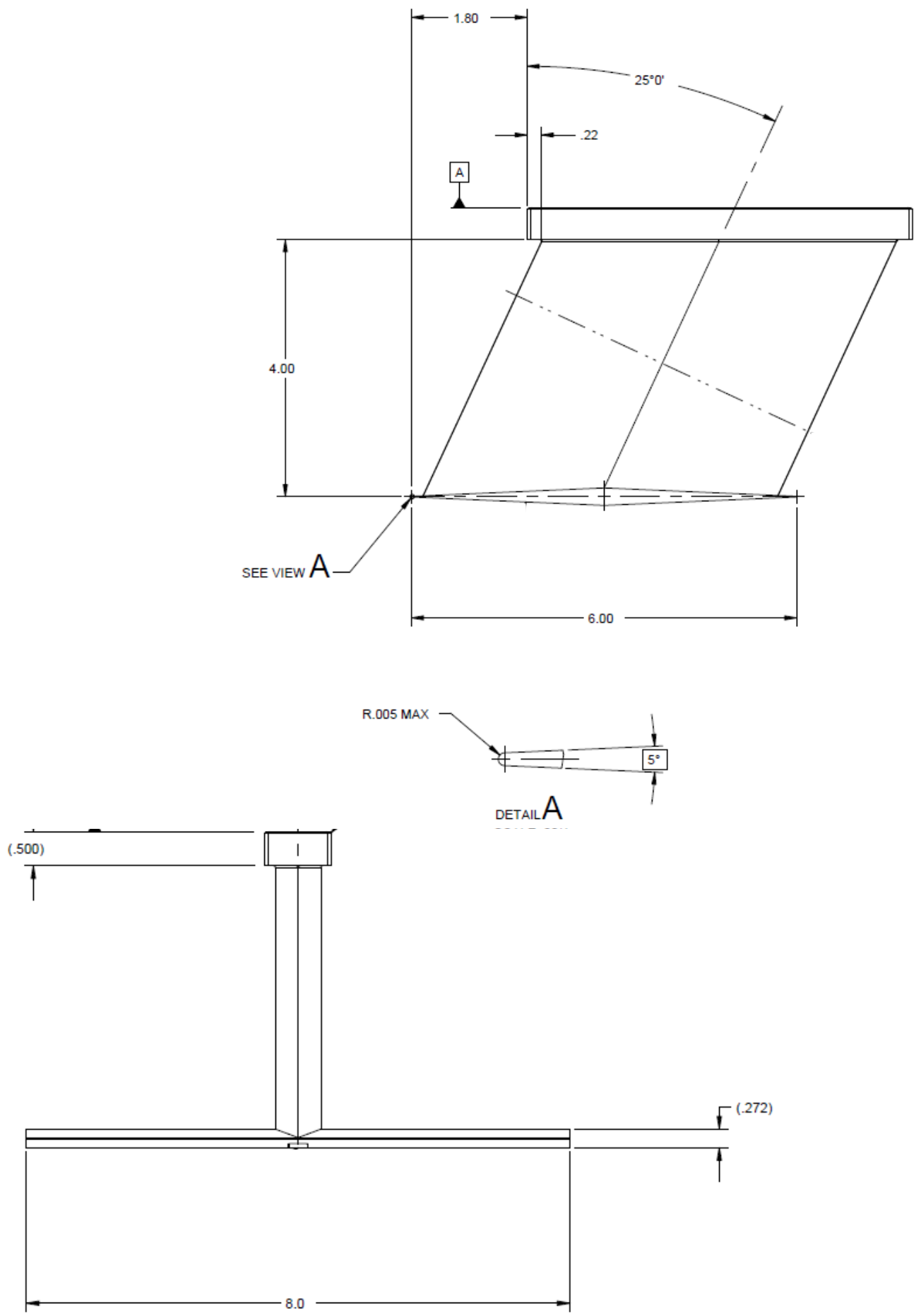

Figure 5. Shock Generator, 2.5-degree is shown.

(NASA Glenn drawing 130303MRA024). 


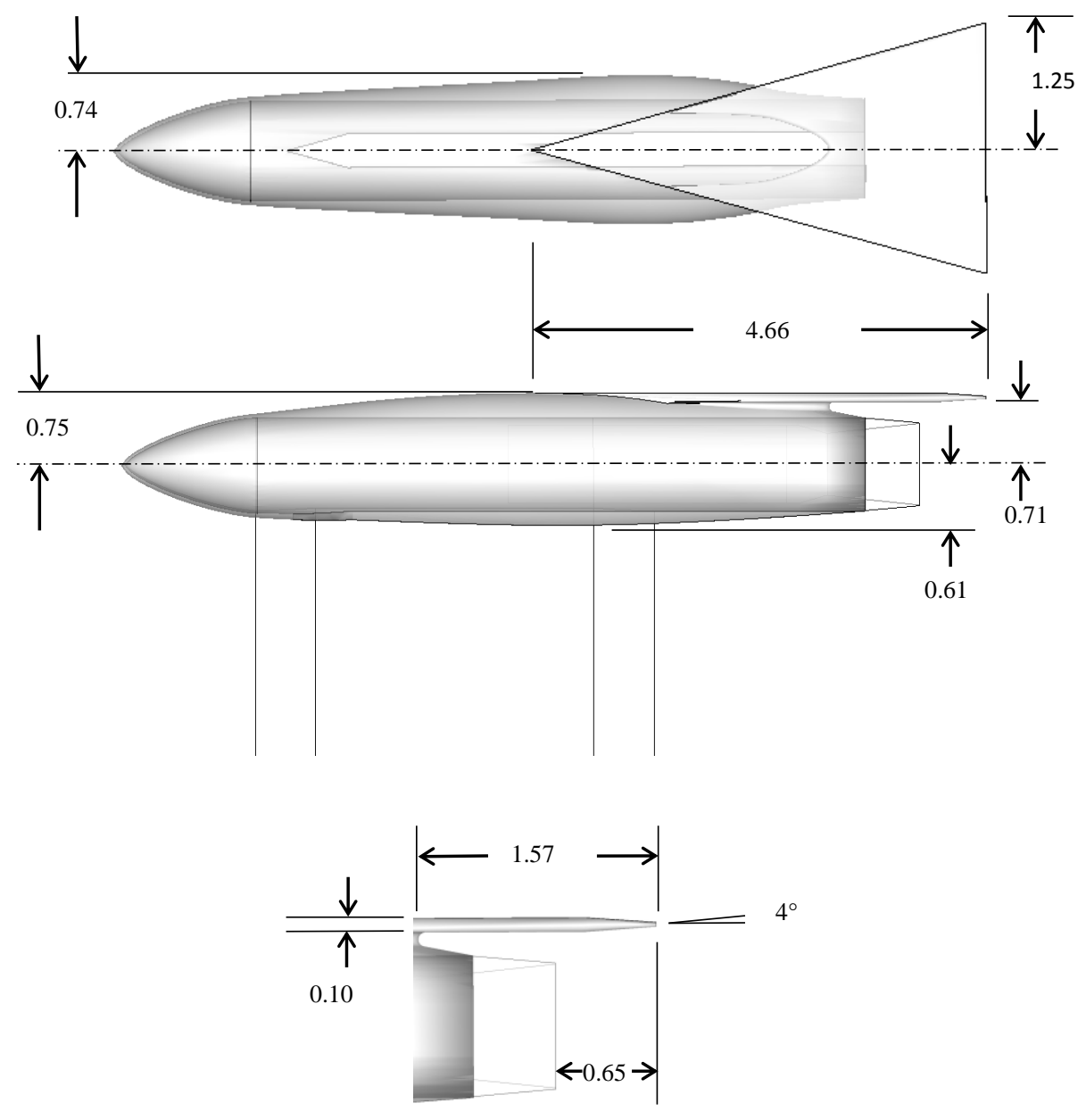

Figure 6. Nacelle and Aft Deck (x/D=0.5). 


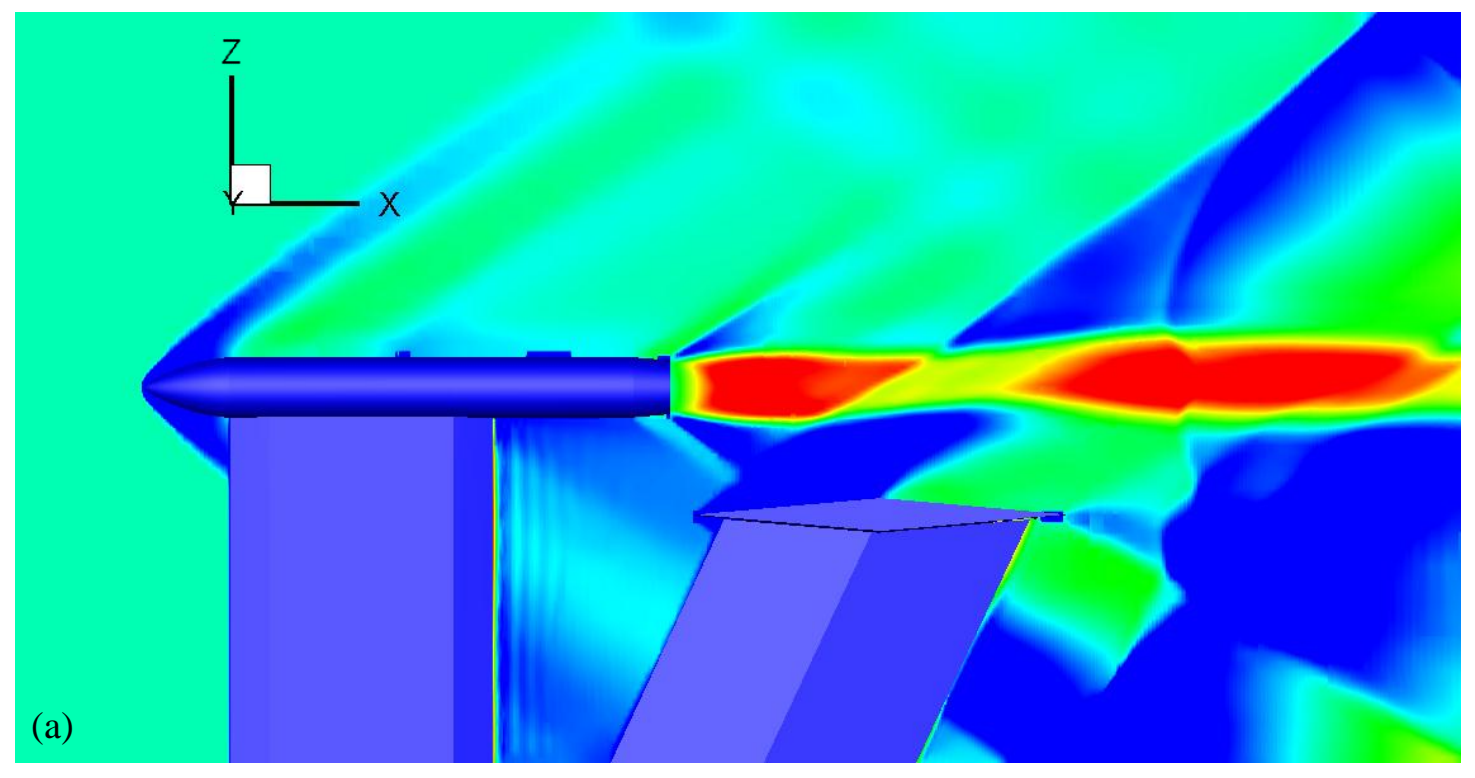

$\begin{array}{llllll}\text { Mach } & 1.7 & 1.9 & 2.1 & 2.3 & 2.5\end{array}$

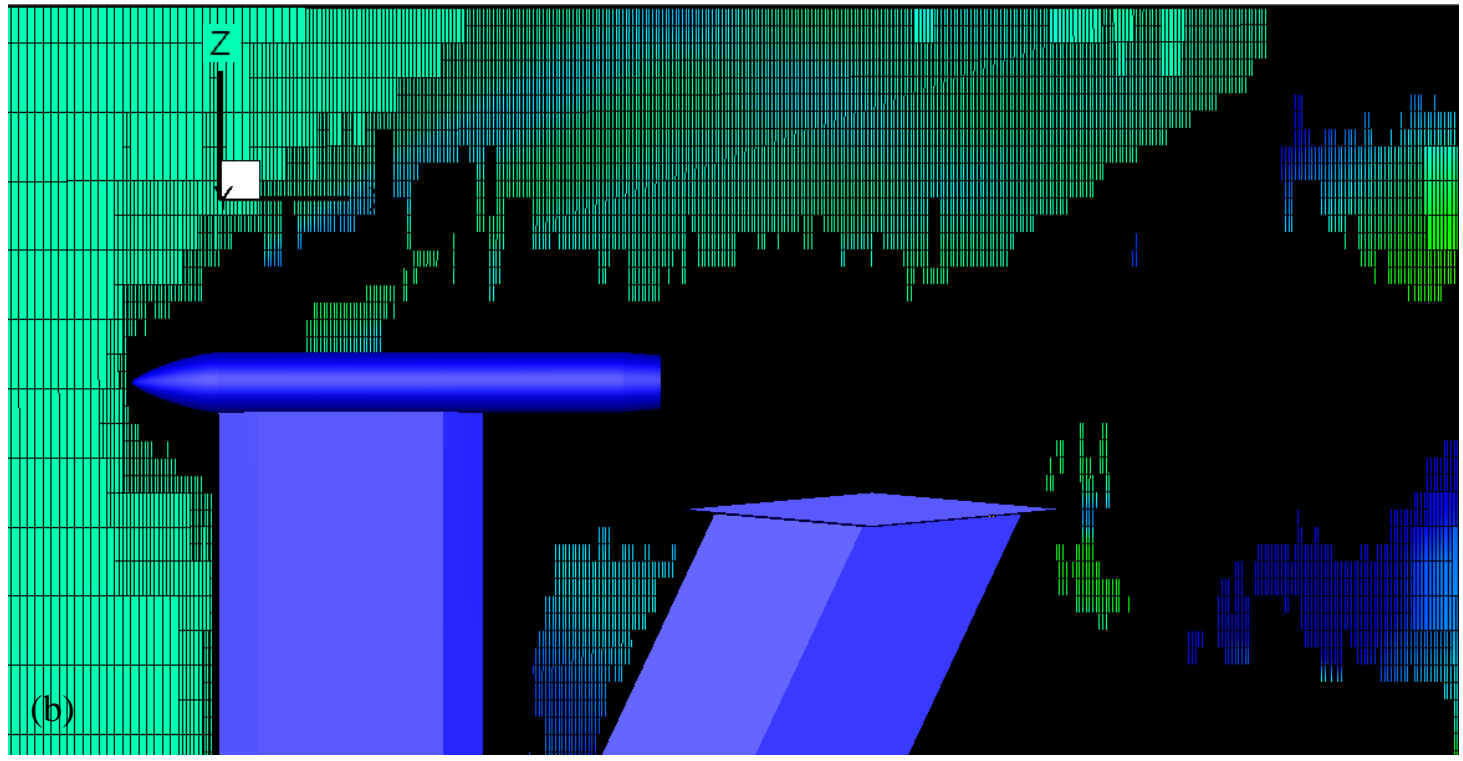

Figure 7. 6-inch long 5-degree wedge shock generator full configuration (a) Mach number contour plot, NPR=12 and (b) mesh. 


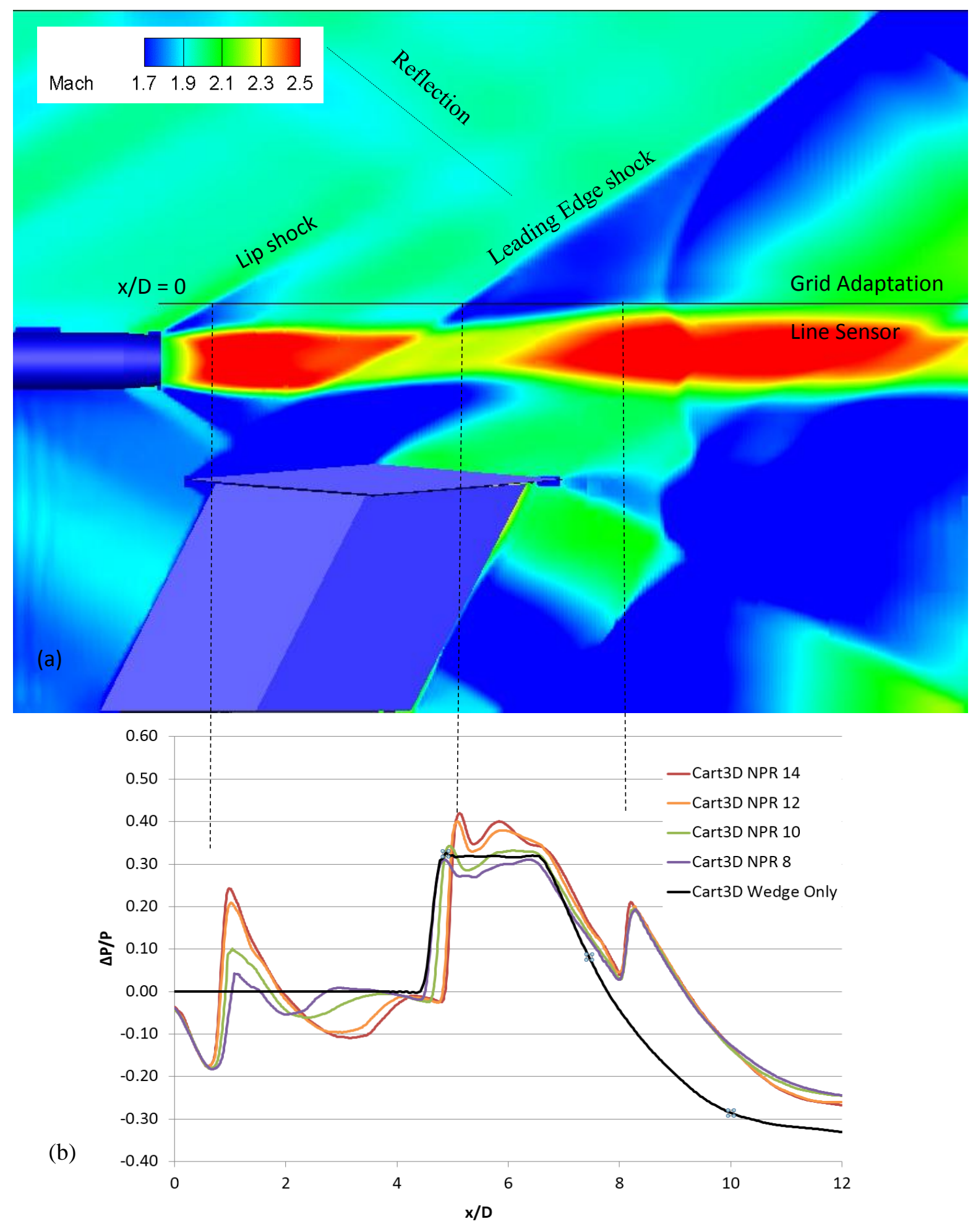

Figure 8. 6-inch long 5-degree wedge shock generator and nozzle (a) Mach contour plot, NPR=12, (b) Cart3D pressure profile at $1 \mathrm{D}$ above nozzle centerline. 


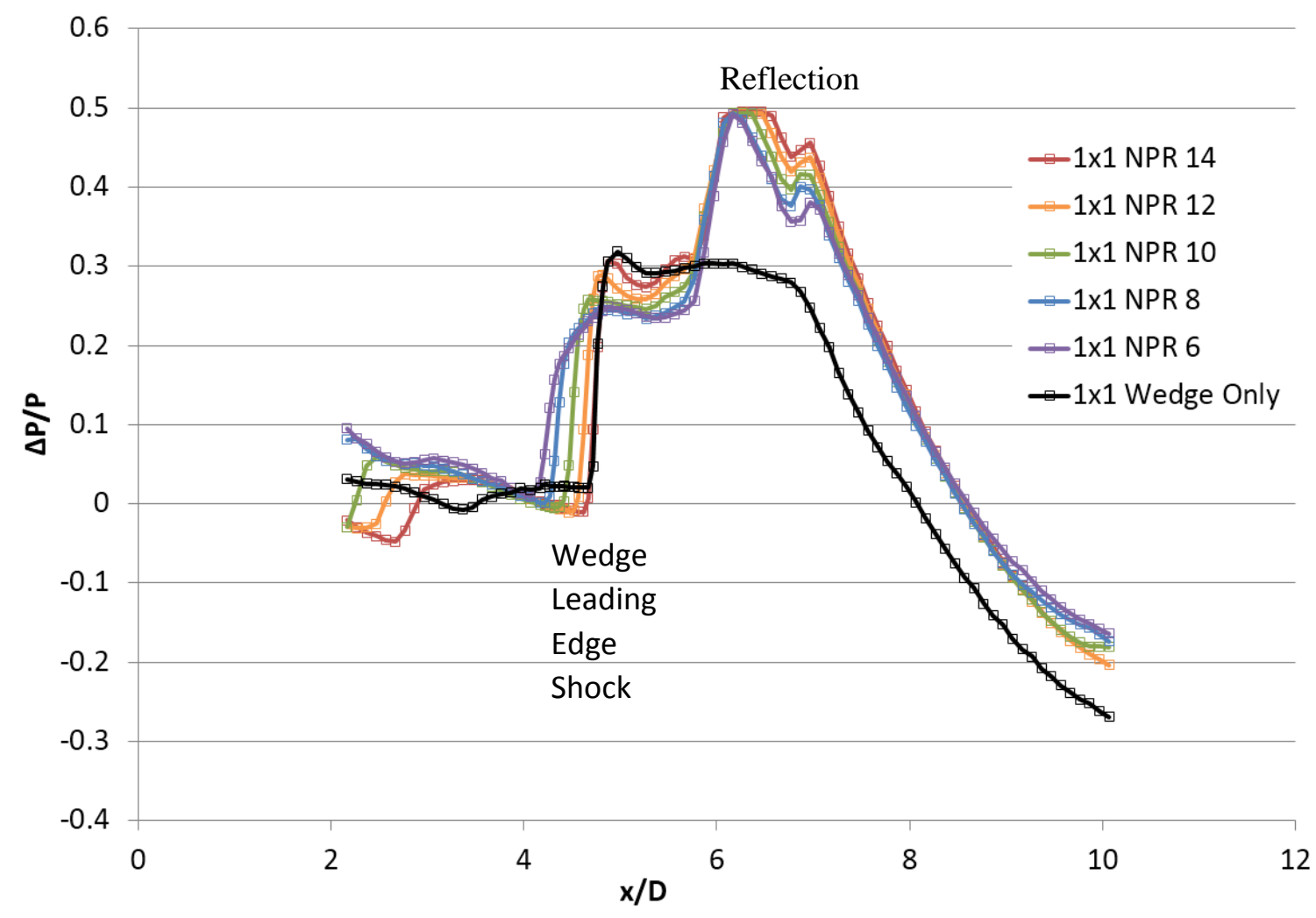

Figure 9. 6-inch long 5-degree wedge shock generator and experimental pressure profiles at 1D above nozzle centerline. 

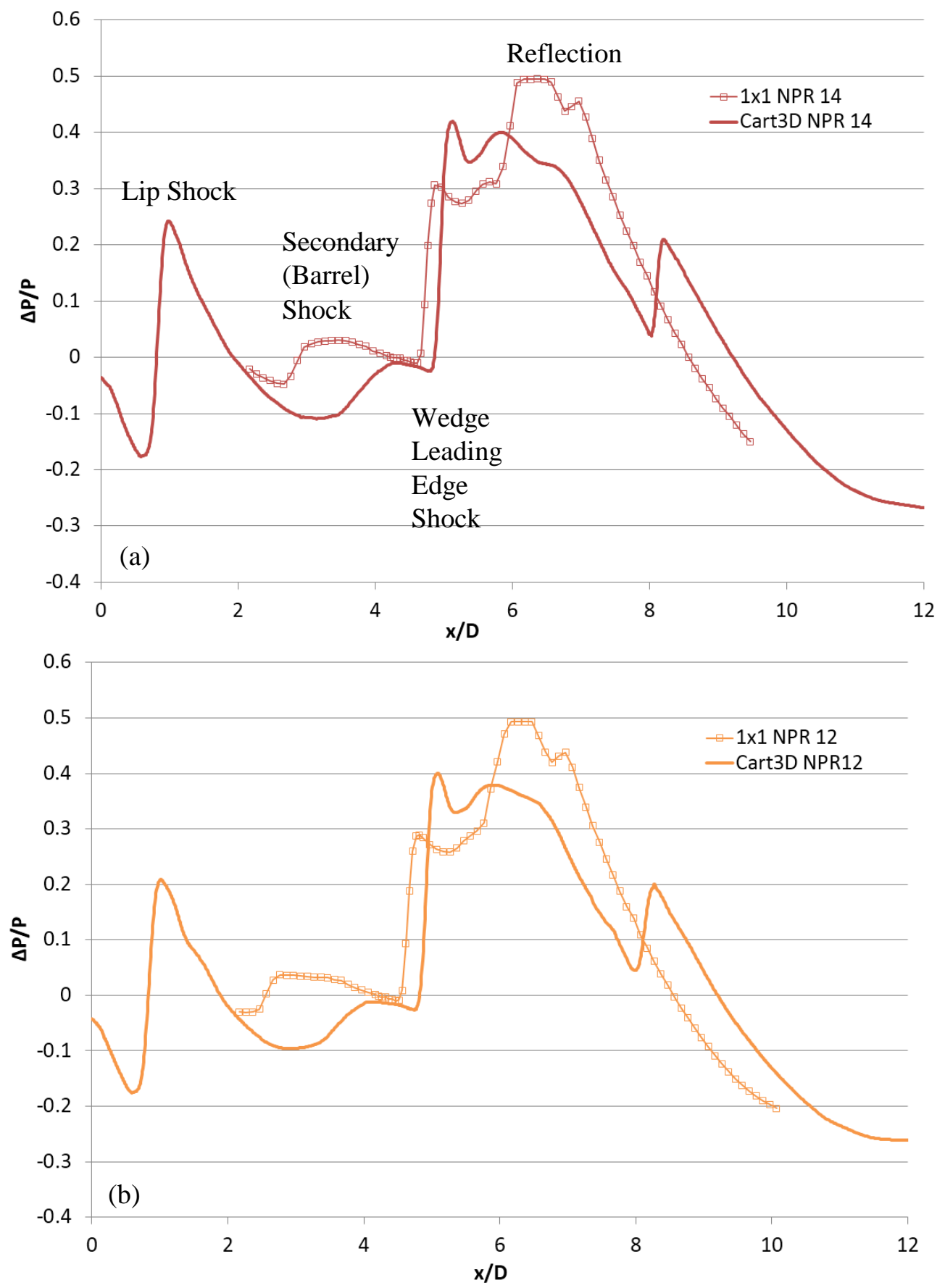

Figure 10. 6-inch long 5-degree wedge shock generator comparison of Cart3D pressure profiles at $1 \mathrm{D}$ for (a) NPR = 14, (b) NPR $=12$, (c) NPR $=10$, (d) NPR $=8$, (e) NPR $=6$, and (f) wedge only. 

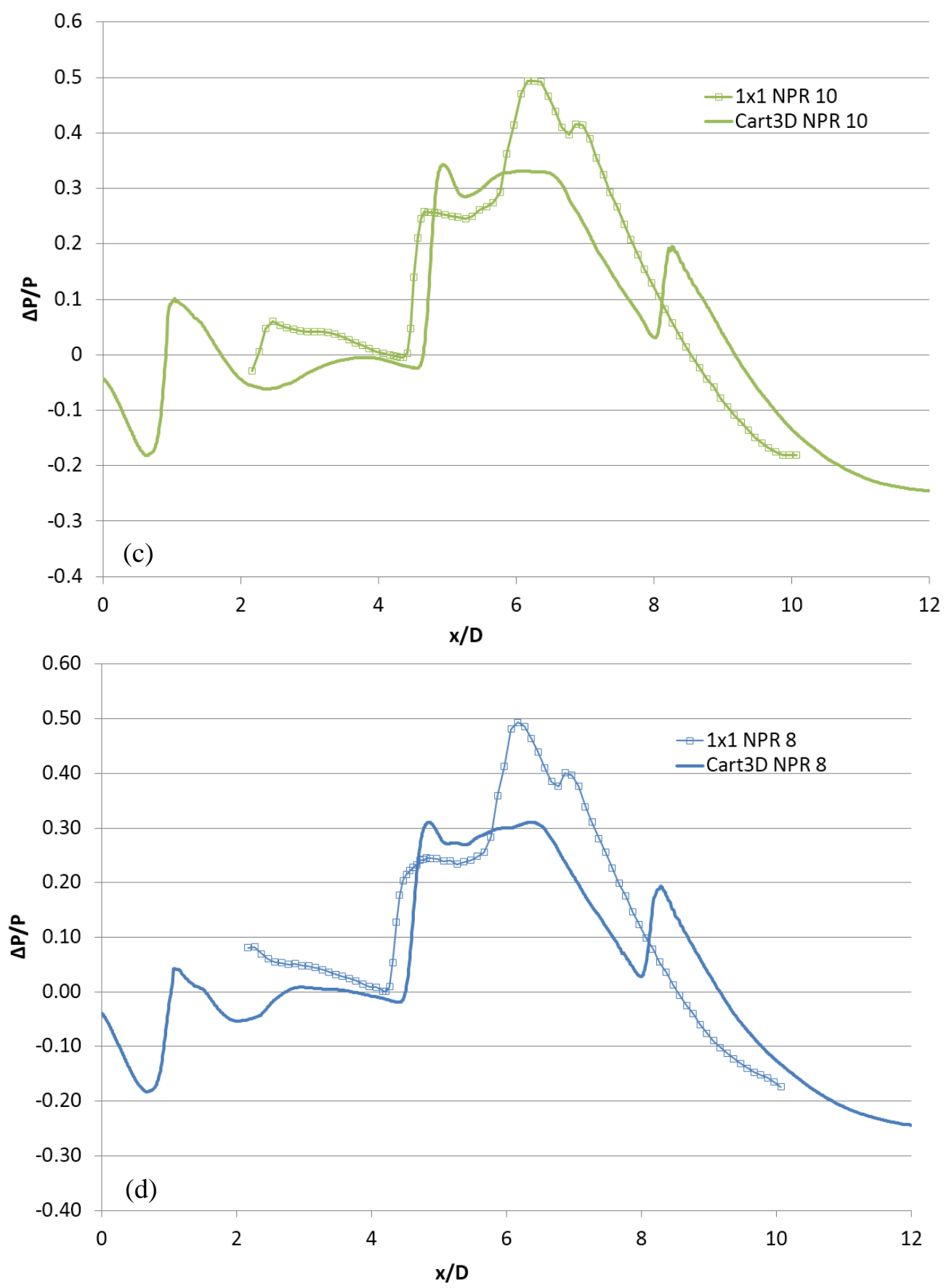

Figure 10 (cont'd). Comparison of Cart3D pressure profiles at 1D for (a) NPR $=14$, (b) NPR $=12$, (c) NPR $=10$, (d) NPR = 8, (e) NPR = 6, and (f) wedge only. 

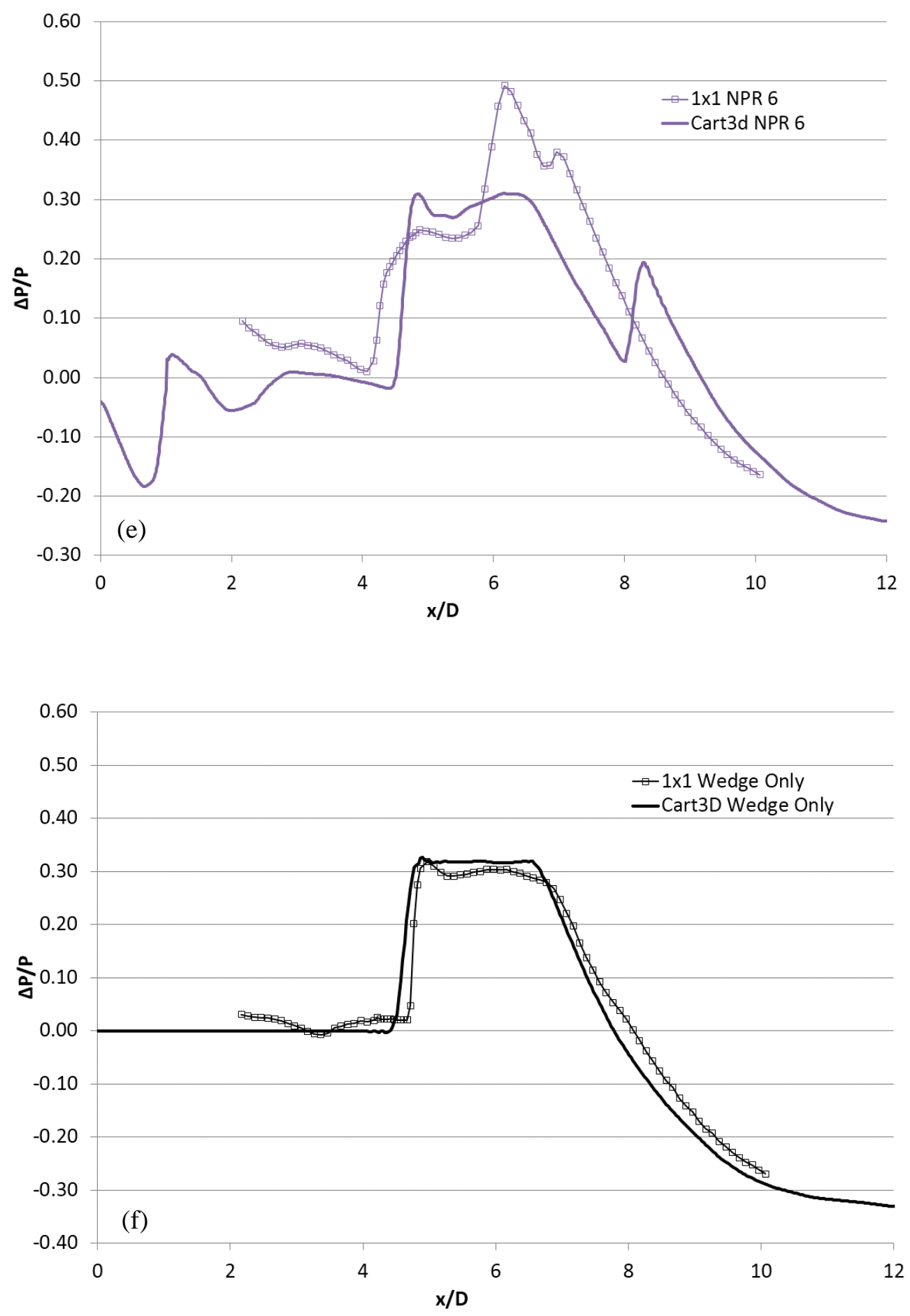

Figure 10 (cont'd). Comparison of Cart3D pressure profiles at 1D for (a) NPR $=14$, (b) NPR $=12$, (c) NPR $=10$, (d) NPR = 8, (e) NPR =6, and (f) wedge only. 


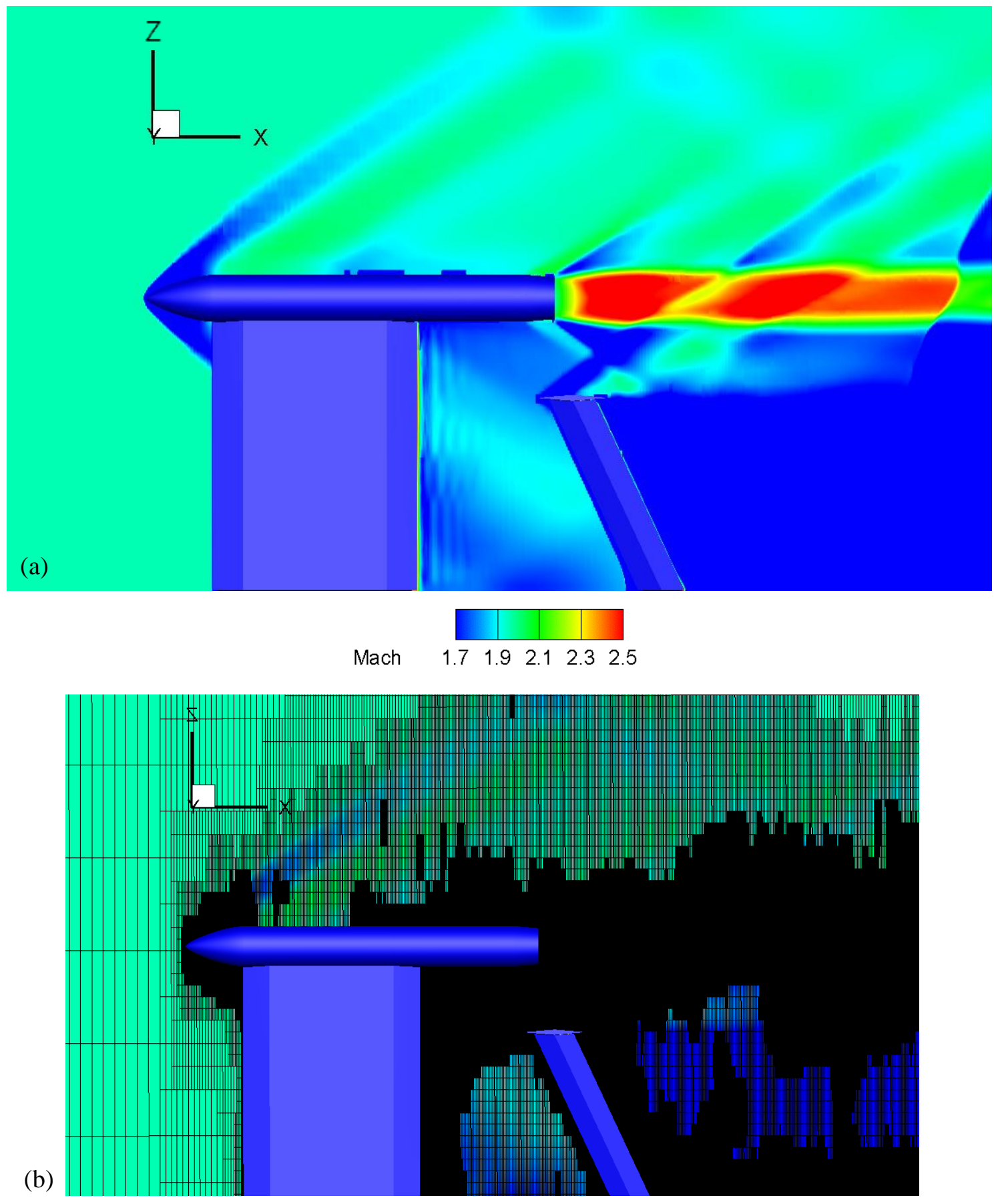

Figure 11. 1.5-inch long 5-degree wedge shock generator full configuration (a) Mach number contour plot, NPR=12, and (b) mesh. 


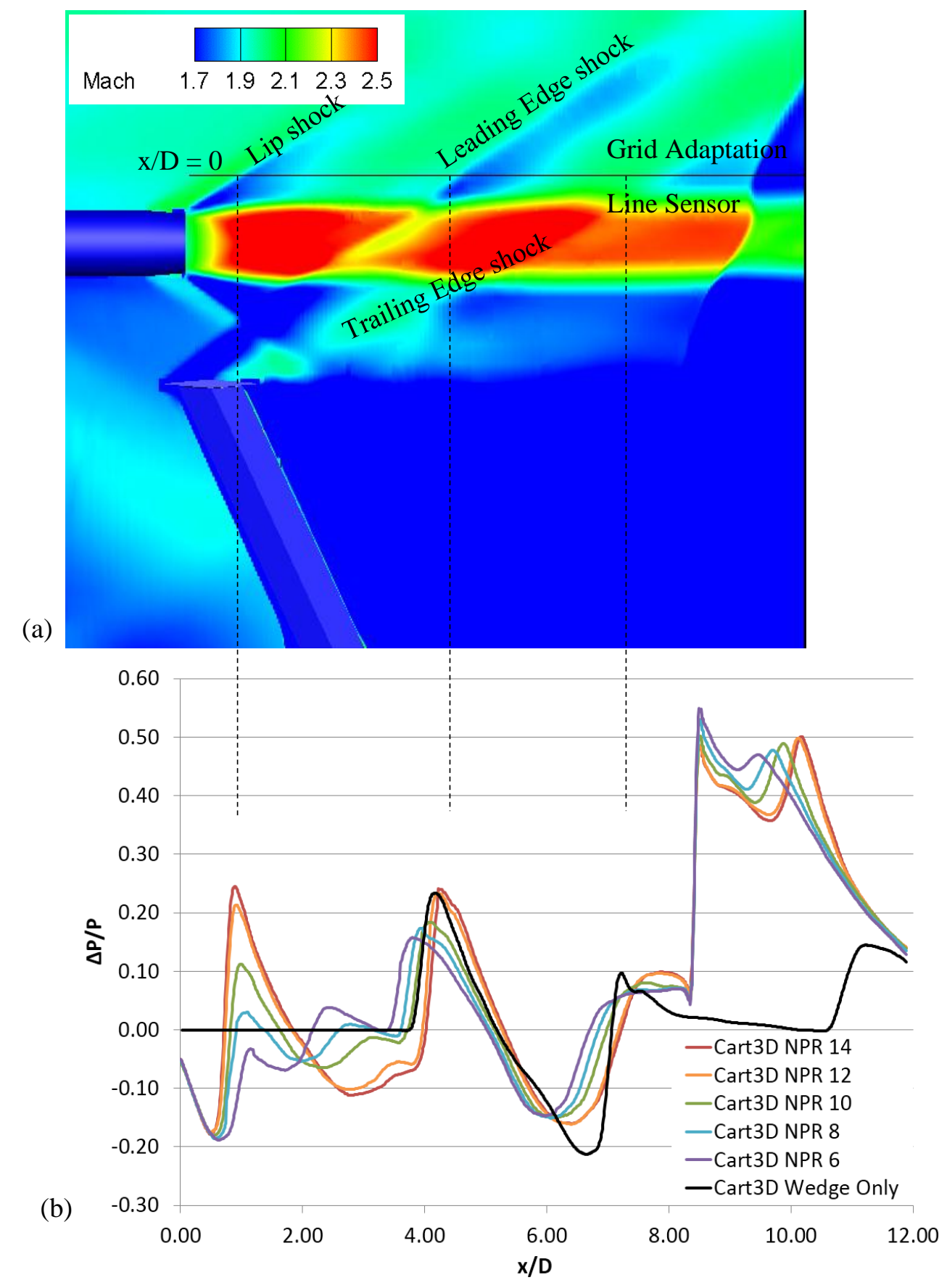

Figure 12. 1.5-inch long 5-degree wedge shock generator and nozzle

(a) Mach number contour plot, NPR=12, and

(b) Cart3 pressure profile at $1 \mathrm{D}$ above the nozzle centerline. 


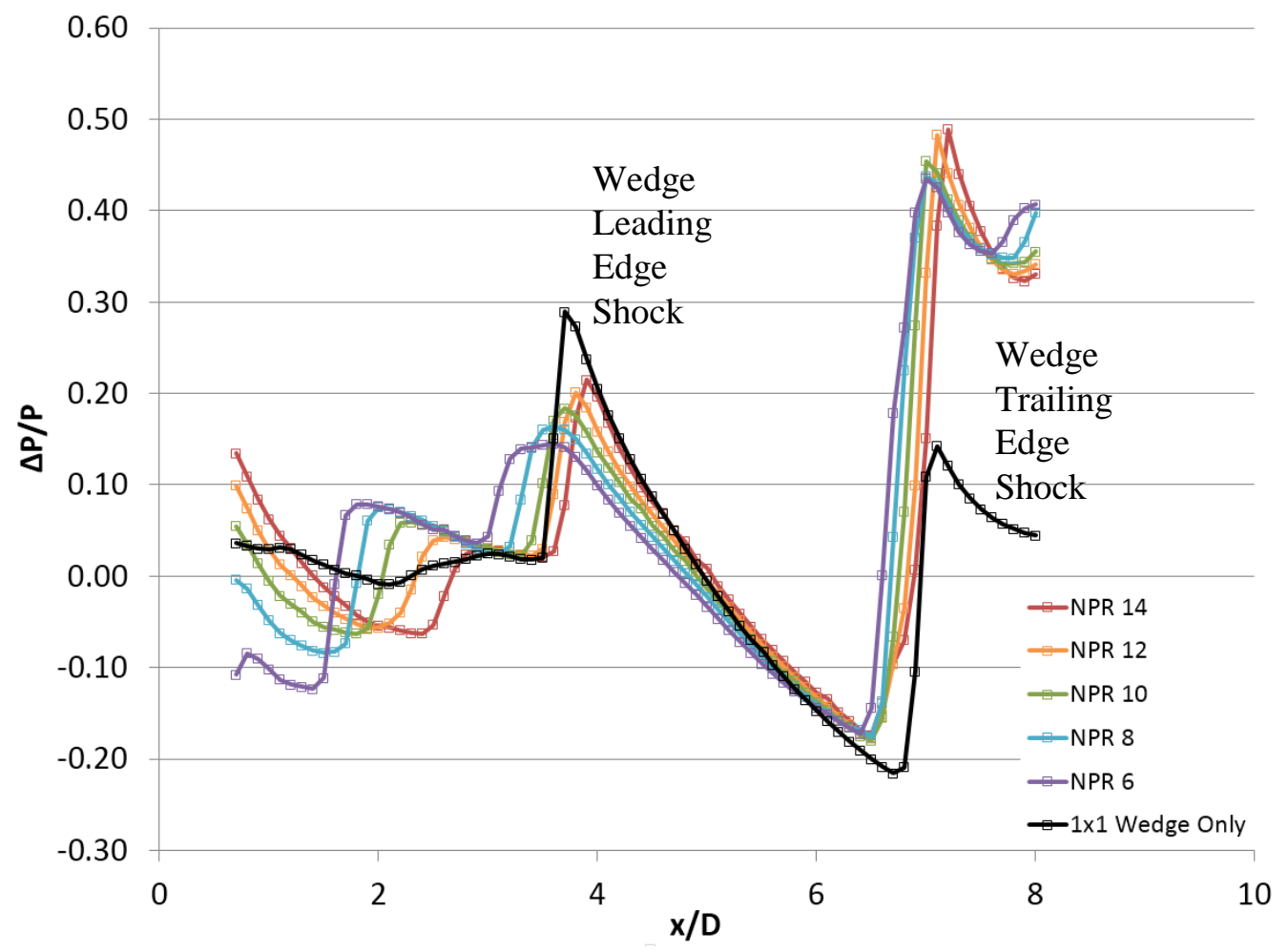

Figure 13. 1.5-inch long 5-degree wedge shock generator experimental pressure profiles at 1D above nozzle centerline. 

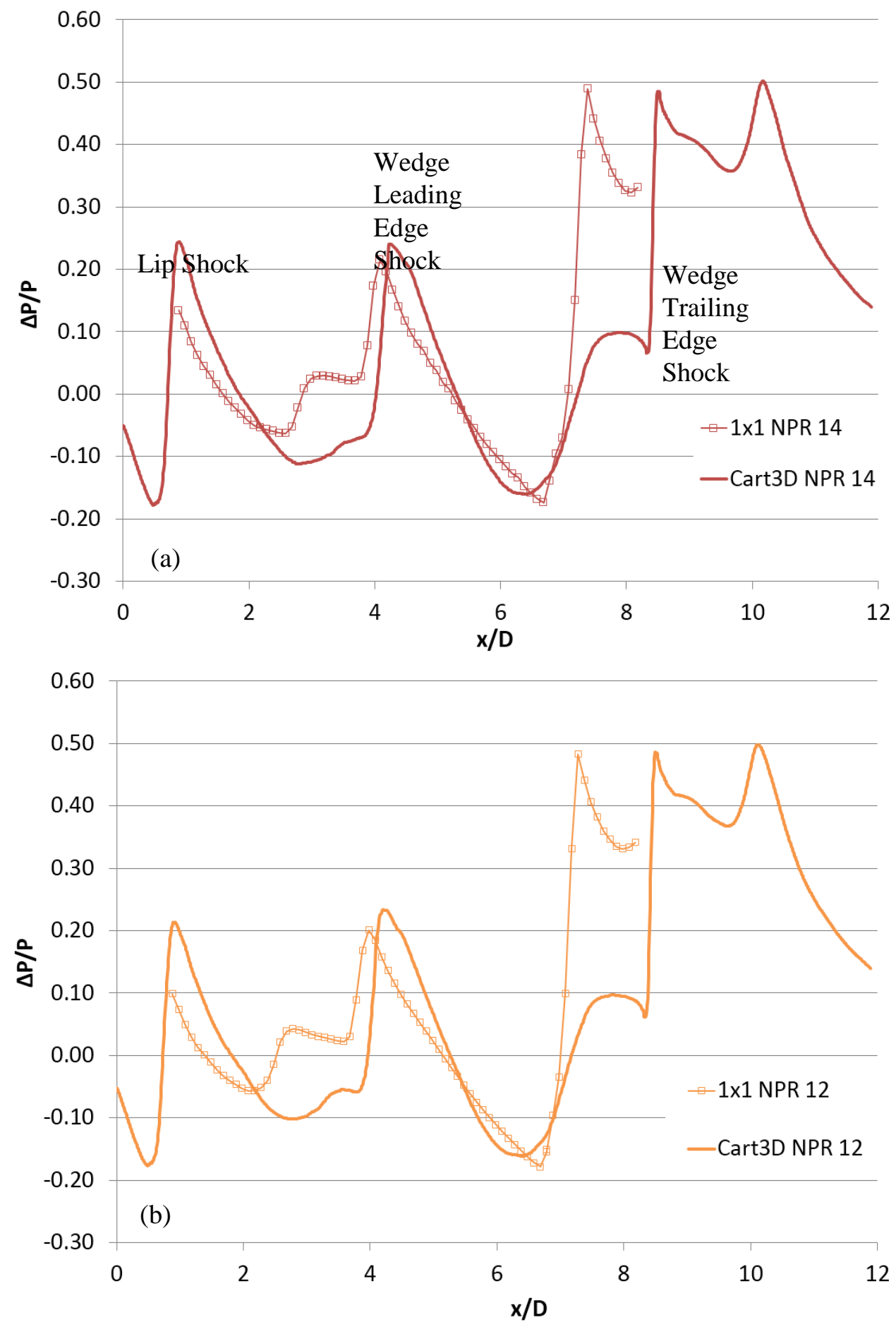

Figure 14. Comparison of Cart3D 1.5-inch long 5-degree wedge shock generator and experimental pressure profiles at 1D above nozzle centerline for (a) NPR $=14$, (b) NPR $=12$, (c) NPR $=10$, (d) NPR $=8$, (e) NPR $=6$. 

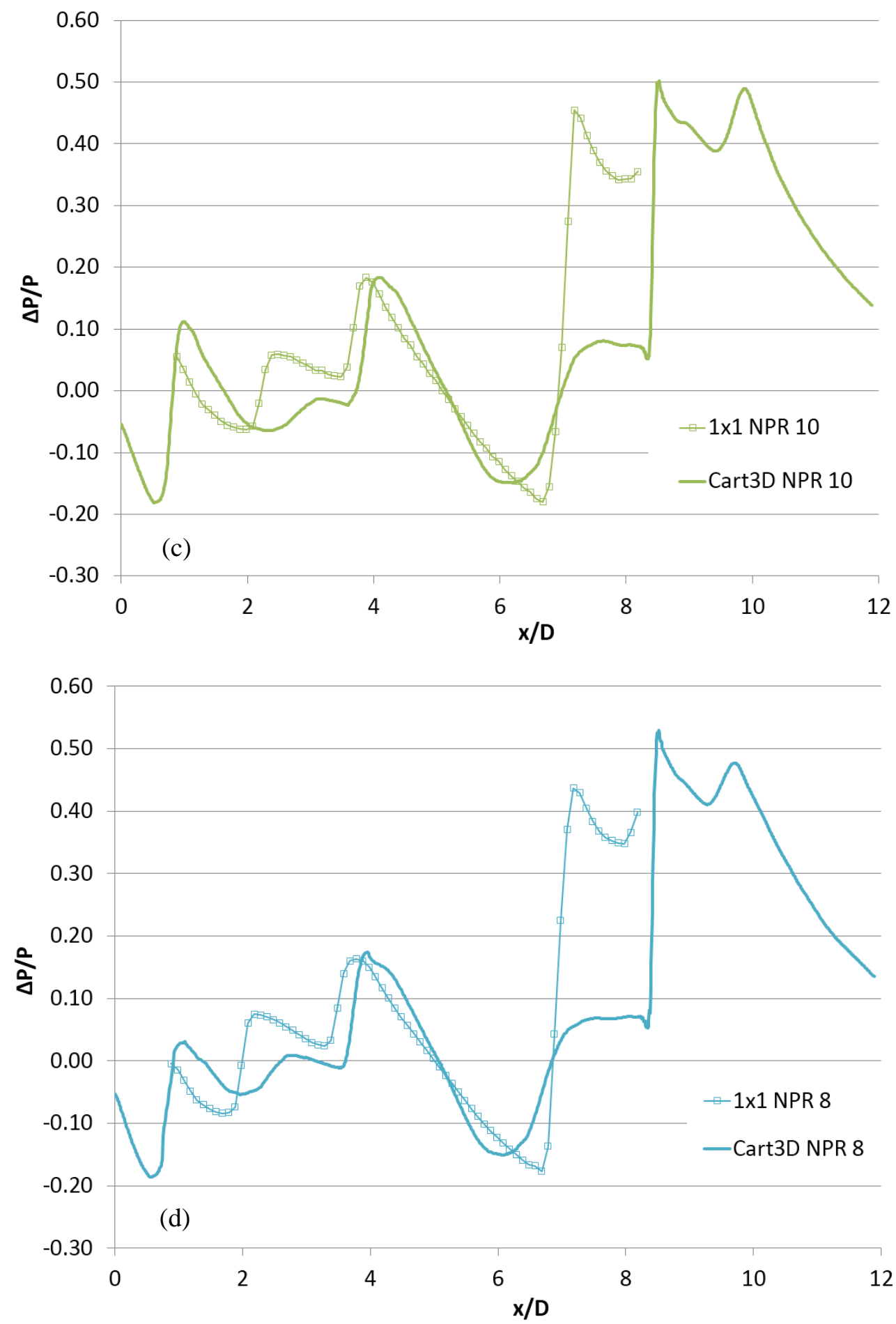

Figure 14 (cont'd). Comparison of Cart3D 1.5-inch long 5-degree wedge shock generator and experimental pressure profiles at 1D above nozzle centerline for (a) NPR $=14$, (b) NPR $=12$, (c) NPR $=10$, (d) NPR $=8$, (e) $\mathrm{NPR}=6$. 


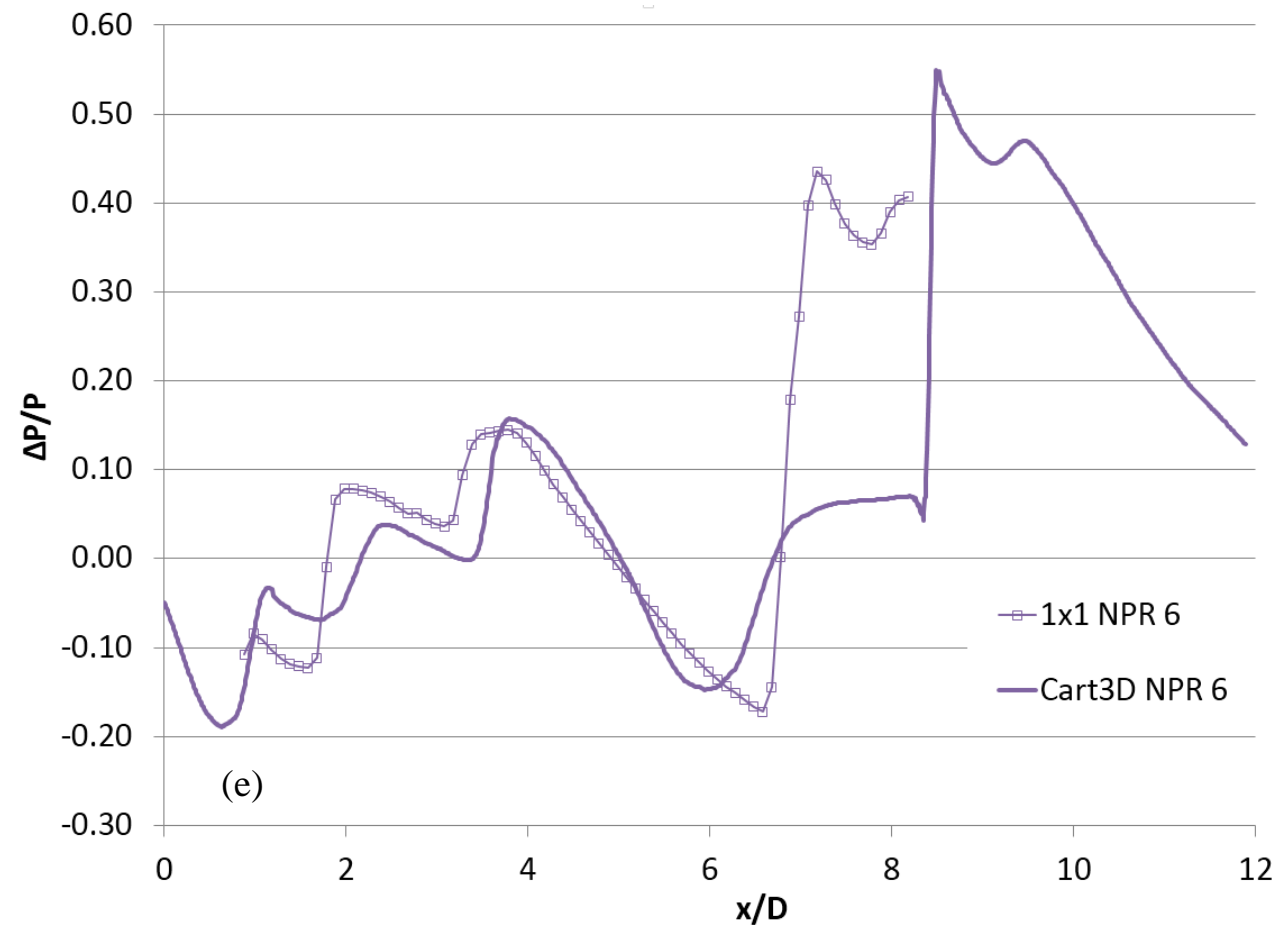

Figure 14 (cont'd). Comparison of Cart3D 1.5-inch long 5-degree wedge shock generator and experimental pressure profiles at 1D above nozzle centerline for (a) NPR $=14$, (b) NPR $=12$, (c) NPR $=10$, (d) NPR $=8$, (e) $\mathrm{NPR}=6$. 


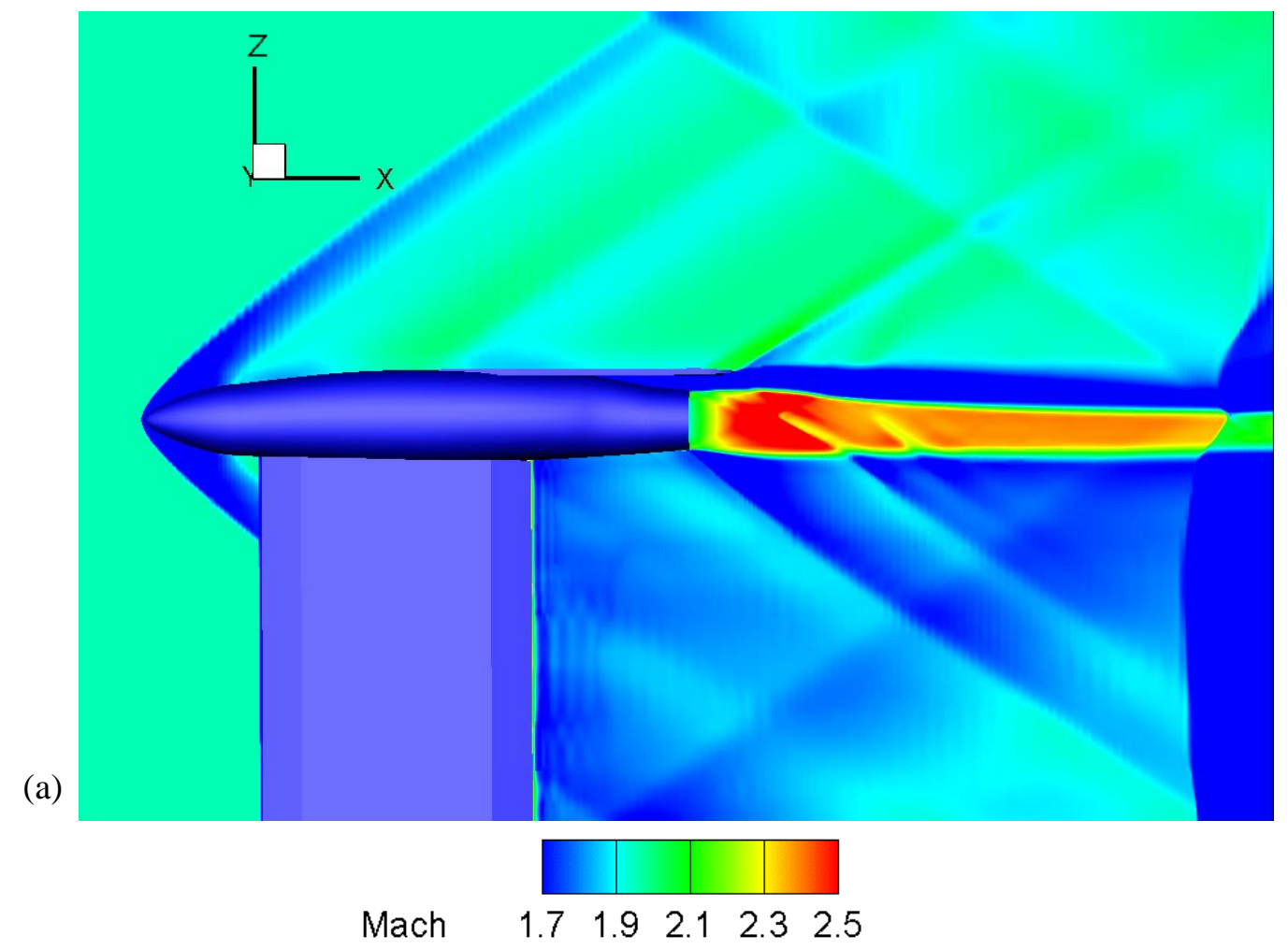

(b)

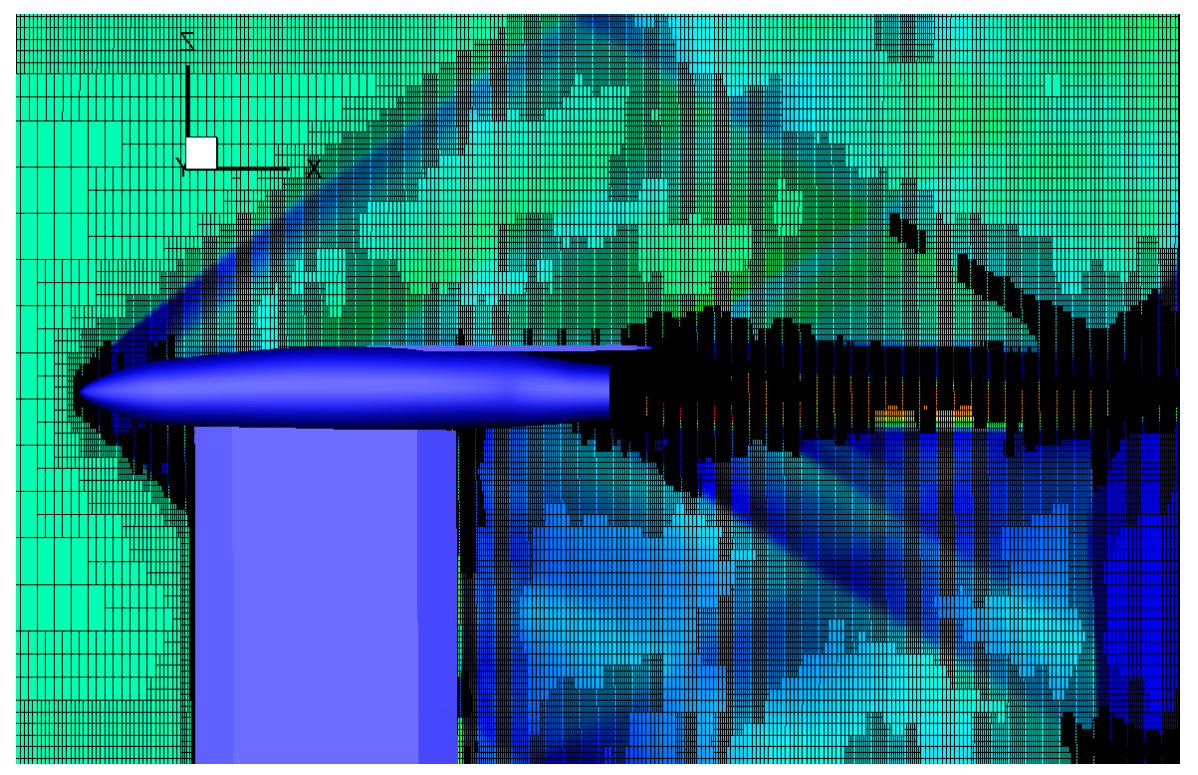

Figure 15. Aft deck (x/D=0.5) shock generator full configuration (a) Mach number contour plot and (b) mesh. 


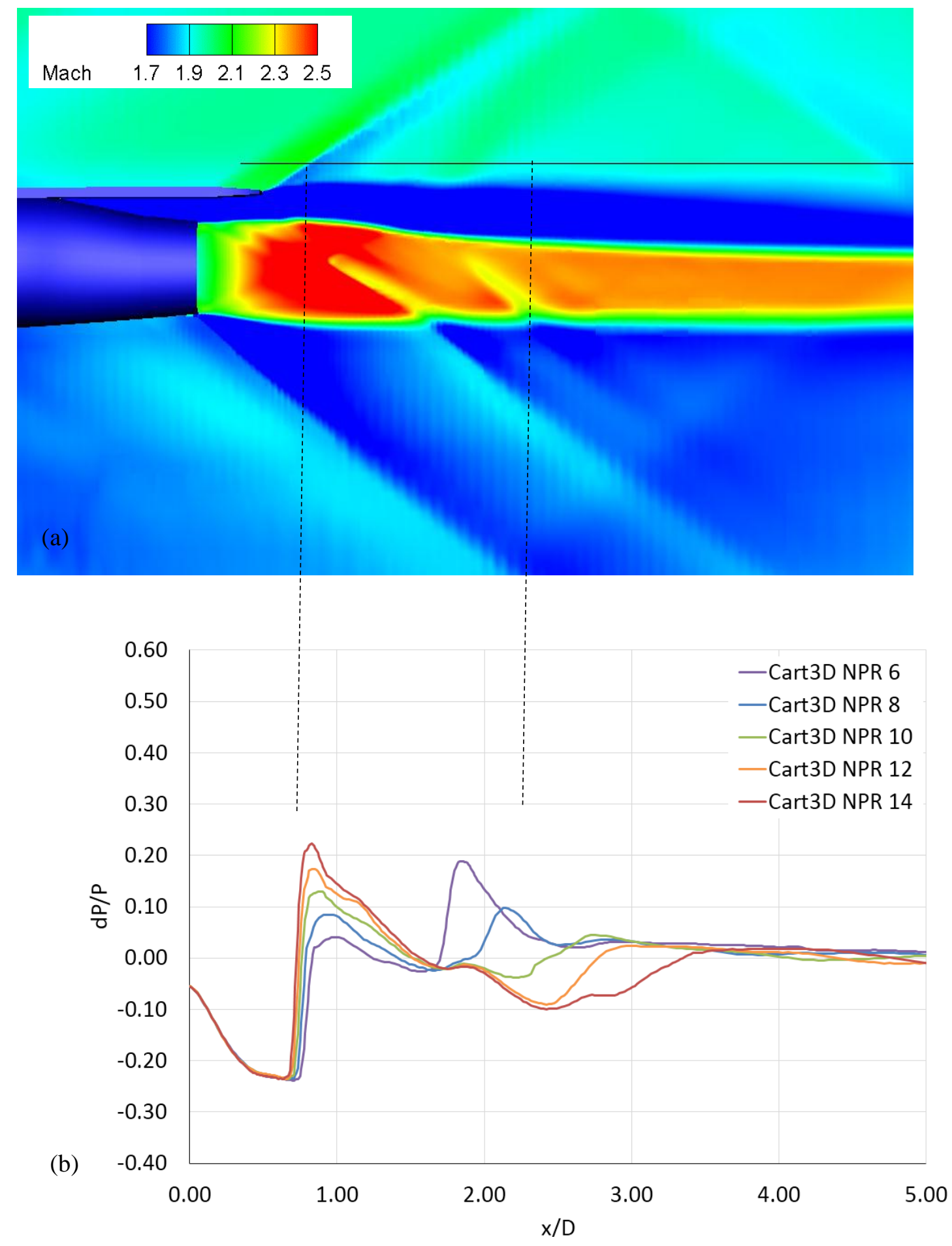

Figure 16. Aft deck (x/D=0.5) shock generator full configuration (a) Mach number contour plot and (b) Cart3D pressure profile at 1D above nozzle centerline. 


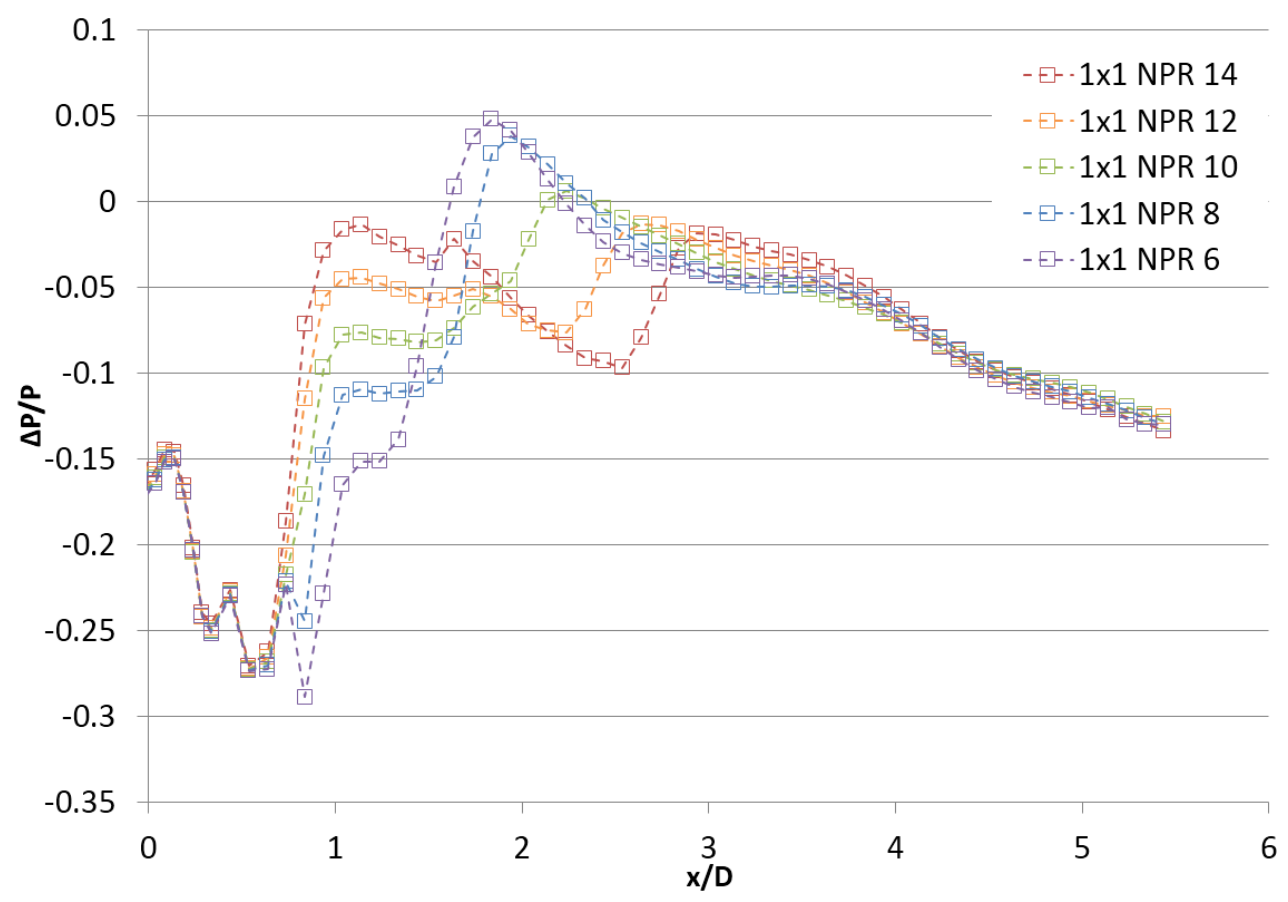

Figure 17. Aft deck $(\mathrm{x} / \mathrm{D}=0.5)$ shock generator experimental pressure profiles at $1 \mathrm{D}$ above nozzle centerline.

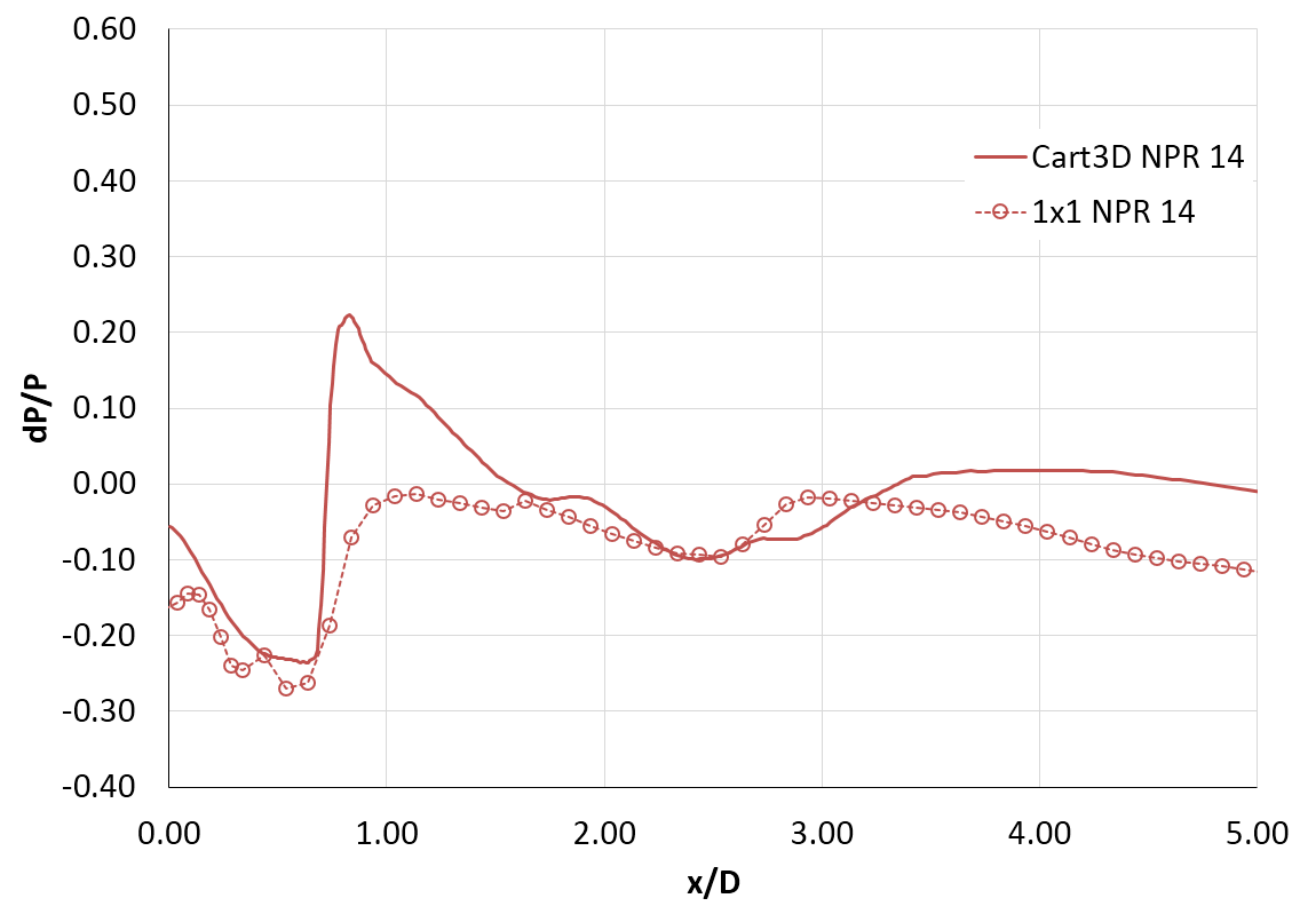

Figure 18. Comparison of aft deck (x/D/0.5) Cart3D pressure profiles at $1 \mathrm{D}$ above nozzle centerline for (a) NPR $=$ 14, (b) NPR $=12$, (c) NPR $=10$, (d) NPR $=8$, (e) NPR $=6$. 

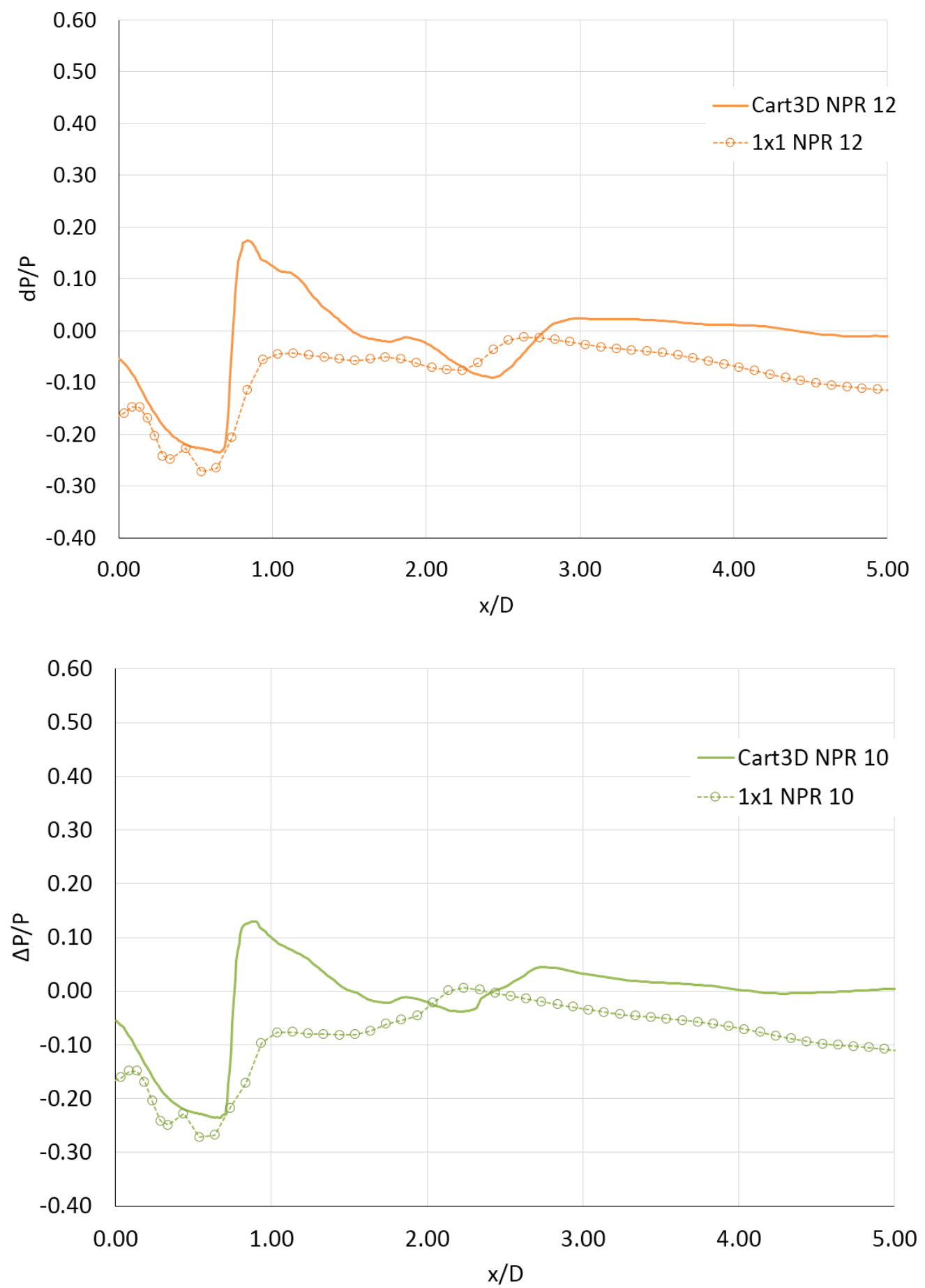

Figure 18 (cont'd). Comparison of aft deck (x/D/0.5) Cart3D pressure profiles at $1 \mathrm{D}$ above nozzle centerline for (a) $\mathrm{NPR}=14$, (b) NPR $=12$, (c) NPR $=10$, (d) NPR $=8$, (e) NPR $=6$. 

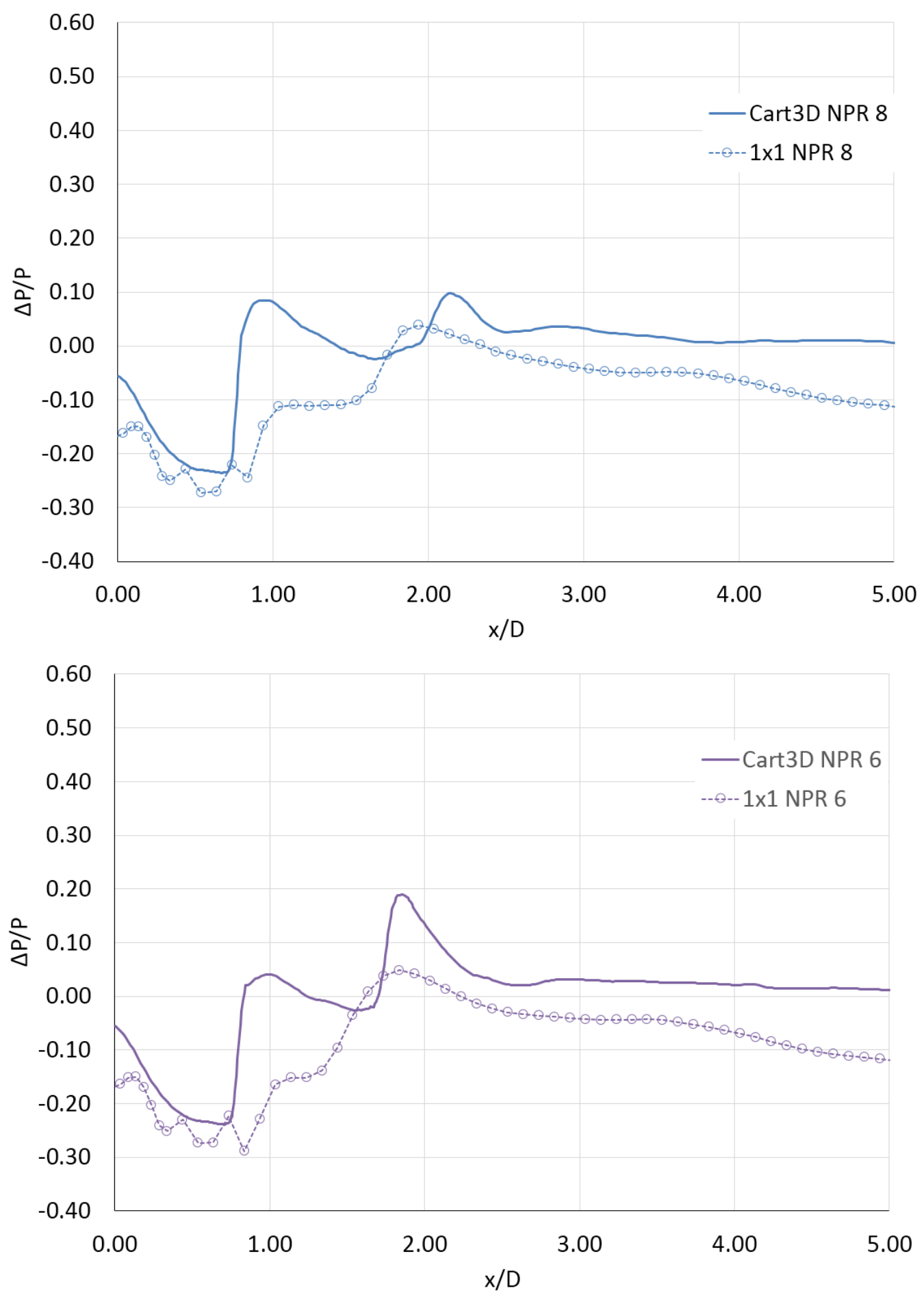

Figure 18 (cont'd). Comparison of aft deck (x/D/0.5) Cart3D pressure profiles at $1 \mathrm{D}$ above nozzle centerline for (a) $\mathrm{NPR}=14$, (b) NPR $=12$, (c) NPR $=10$, (d) NPR $=8$, (e) NPR $=6$. 